\title{
Pension reform and labor market incentives
}

\author{
Walter H. Fisher • Christian Keuschnigg
}

Received: 9 July 2007 / Accepted: 2 October 2008 /

Published online: 26 November 2008

(C) Springer-Verlag 2008

\begin{abstract}
This paper investigates how parametric reform in a pay-as-you-go pension system with a tax-benefit link affects retirement and work incentives of prime-age workers. We find that postponed retirement tends to harm incentives of prime-age workers in the presence of a tax-benefit link, thereby creating a policy trade-off in stimulating aggregate labor supply. We show how several popular reform scenarios are geared either towards young or old workers or, indeed, both groups under appropriate conditions. We characterize the excess burden of pension insurance and show how it depends on the supply elasticities of both decision margins and the effective tax rates.
\end{abstract}

Keywords Pension reform $\cdot$ Retirement - Tax-benefit link

JEL Classification $\mathrm{H} 55 \cdot \mathrm{J} 26$

\section{Introduction}

In light of the concerns faced by policy makers regarding the long-run funding of public pensions, many countries have initiated reforms. Apart from the need

Responsible editor: Alessandro Cigno

W. H. Fisher

Institute for Advanced Studies, Stumpergasse 56, 1060 Vienna, Austria

C. Keuschnigg $(\bowtie)$

CEPR and CESifo, University of St. Gallen (IFF-HSG),

Varnbuelstrasse 19, 9000 St. Gallen, Switzerland

e-mail: Christian.Keuschnigg@unisg.ch 
to restore sustainability to pension systems, these reforms are importantly motivated by the concerns regarding the potentially adverse consequences of existing programs for labor market incentives. For these reasons, most countries have initiated reforms that (1) strengthen the tax-benefit link by, for instance, bringing more people into a harmonized pension system in which pensions are assessed on the basis of past earnings, and (2) introduce more actuarial fairness in order to provide disincentives, or "penalties,"for early retirement and to improve the incentives for labor market participation of older workers nearing retirement. It has been long recognized that the tax character of pension contributions tends to discourage work effort of the actively employed (intensive labor supply). This has led policy makers to propose a tighter tax-benefit link to reduce distortions in the labor supply decision faced by younger workers. More recently, the date, or timing, of the retirement decision has received increasing attention. To raise the average retirement age, recent reforms often include adjustments of the pension size to provide stronger incentives for continued work (extensive labor supply). ${ }^{1}$

The important interactions between the incentives facing younger and older workers are less well-known. Rewarding late retirement might have adverse consequences for implicit taxes borne by younger workers. Some reform alternatives might succeed in strengthening labor supply on both margins by encouraging work effort of younger workers and, simultaneously, participation of older workers. Other scenarios might favor one margin at the expense of the other, with possibly no clear-cut net effect on aggregate labor supply. The goal of this paper is to develop a formal model that helps to clarify how the incentives of young and old workers interact and how pension reforms might give rise to either off-setting or mutually reinforcing effects on aggregate labor supply.

There is a large literature on pension economics and old-age insurance; see, for example, Feldstein and Liebman (2002), Bovenberg (2003), Lindbeck and Persson (2003), and Fenge and Pestieau (2005) for a few important reviews. The recent policy debate in the USA has focussed to a great extent on the choice between increased capital funding (e.g., Kotlikoff 1997; Feldstein 2005a, b; Feldstein and Samwick 2002) vs parametric reform of existing pay-as-you-go (PAYG) systems (e.g., Diamond 2004; Diamond and Orszag 2005). Apart from its impact on national savings, the potential labor market implications of public pensions have always played an important role in this debate. An on-going concern is the effect on intensive labor supply, i.e., hours worked by the active generation. In this regard, the crucial question is the extent to which the contributions to social security are actually perceived as a tax by the active generation. The answer depends, of course, on the institutional design of the PAYG system. In a system with a tax-benefit link in which pensions are based on past earnings, the effective tax rate can amount

\footnotetext{
${ }^{1}$ Policies to encourage earlier retirement are not unknown, however. See Bratberg et al. (2004) for an analysis of an early retirement program that was instituted in Norway in 1989.
} 
to roughly half of the statutory contribution rate, as recent calculations for Germany by Fenge and Werding (2004) have shown. Beginning with Feldstein and Samwick (1992), the existing literature has calculated a much higher tax component for young workers far from retirement, while the effective tax is, in contrast, much lower for workers nearing retirement. Disney (2004) provided recent computations of the effective tax rates implied by PAYG contributions and econometric estimates of the employment effects. The results are consistent with usual findings of the empirical literature on intensive labor supply, namely, that male employment is not particularly responsive to tax incentives, while female activity rates are highly adversely affected by the effective contribution tax.

According to the influential studies of Gruber and Wise (1999a, b, 2002), a serious problem associated with PAYG systems is that they impose significant disincentives to work at older ages. Gruber and Wise (2005) provide calculations for the relationship between later retirement and the additional benefits that lead to actuarial fairness. Börsch-Supan (2000, 2003) provides evidence on the participation decisions of older German workers. Scarpetta (1996) finds empirical evidence supporting this phenomenon in a cross-country study. A major factor behind the "trend" toward early retirement is that existing PAYG systems distort the labor supply decision on the extensive margin and thereby encourage early retirement. Blöndal and Scarpetta (1999) suggest that early retirement provisions in many countries have led to a dramatic decrease in the labor force participation among older workers. The fact that benefits are not adjusted in an actuarially fair manner is a key reason for this large distortion on the extensive margin. Theoretical work on social security and retirement decisions is inspired by the seminal contributions of Feldstein (1974), Sheshinski (1978), and Diamond and Mirrlees (1978). More recent theoretical contributions on the (optimal) design of pension systems in the presence of a retirement decision are found, for example, in Breyer and Kifmann (2002), Cremer and Pestieau (2003), and Cremer et al. (2004). ${ }^{2}$

The novel contribution of this paper is to shed more light on how the structure of existing PAYG pension systems simultaneously affects the intensive and extensive margins of labor supply. In particular, the paper will show how the effective tax rate on the intensive labor supply of younger workers and the participation tax rate faced by older workers, and, thus, the extensive and intensive labor supply responses, interact with each other. How they interact depends crucially on the specific institutional design of the system. We are able to provide a sharper characterization of the excess burden of a PAYG pension system that brings out the parallels with the recent literature, found

\footnotetext{
${ }^{2}$ See Fenge and Pestieau (2005) for a review. Breyer and Hupfeld (2007) point out the distributional effects of pension reform towards more actuarial fairness. Bommier et al. (2005) emphasize redistribution towards the short-lived, while Cremer et al. (2004) focus on redistribution towards the ill. The redistributional implications of retirement incentives are, nevertheless, not the focus of this paper.
} 
in Kleven and Kreiner (2006), Immervoll et al. (2007), and Saez (2002), on labor taxation in the presence of intensive and extensive supply. We show how the excess burden depends (1) on the behavioral elasticities with respect to prime-age labor supply and the retirement decision of older workers and (2) on the effective tax rates for these two groups. We then turn to parametric pension reform and derive the behavioral response and welfare implications of strengthening the tax-benefit link and introducing more actuarial fairness by making the pension eligibility rules more sensitive to the choice of the retirement date. These are important reform strategies chosen by numerous countries in the recent past. To our knowledge, a rigorous analysis of a marginal reform of the tax-benefit link by making it more sensitive with respect to retirement age is also novel. ${ }^{3}$

To focus on the essential mechanisms, the model we consider is a simple one. Agents are risk-neutral, live two periods, and make an intensive labor supply decision when young and an extensive, participation choice in the second period of life. Production technology is Ricardian and labor markets are competitive. Consumer-workers make their choices subject to a general pension earnings rule that conveniently parameterizes different degrees of actuarial fairness and encompasses the most important specifications of actual pension systems: (1) a Beveridge-type system in which "flat" old-age earnings are independent of contributions; (2) a Bismarckian PAYG system that incorporates a constant tax-benefit link, although one that is not sensitive to the chosen retirement age and is, thus, actuarially unfair; (3) a modified PAYG system that actuarially adjusts-in the sense of Gruber-Wise- the pension rule according to the participation decision; and (4) a fully funded system in which contributions yield the market rate of interest and pension earnings are adjusted to take into account the chosen length of the retirement period.

The rest of the paper is organized as follows: Section 2 describes the households and their intensive and extensive labor supply decisions subject to the structure of the PAYG system. This part of the paper also outlines the equilibrium OLG framework and calculates the responses of intensive and extensive work effort to a socioeconomic trend toward early retirement, including its impact on the pension system. In Section 3, we introduce the welfare measure, compute the consequences of a higher statutory contribution rate, and characterize the marginal excess burden resulting from the expansion of the system. Section 4 is devoted to parametric pension reform, including several scenarios of strengthening the tax-benefit link and introducing a greater degree of actuarial fairness. The paper closes in Section 5 with a brief summary.

\footnotetext{
${ }^{3}$ While it is a crucial issue, an analysis of the political sustainability of the reform scenarios we consider is beyond the scope of this paper. See Galasso and Profeta (2004) for a quantitative political economy model of pension reform in an ageing society with an endogenously chosen PAYG contribution rate.
} 


\section{The model}

\subsection{Households}

In order to concentrate on labor market behavior of young and old workers, we keep the macroeconomic framework as simple as possible. Regarding representative consumer-workers, we assume they live two periods and are risk-neutral. Leaving aside issues related to savings, we make the simplifying assumption that present and future consumption, $c_{t}, t=1,2$, are prefect substitutes. In other words, agents care only about the present value and not the timing of consumption. In assuming a Ricardian framework, labor productivity is the same in both periods and is fixed at unity. ${ }^{4}$ With competitive labor markets, the (real) wage is also unity, MPL $=W=1$, and there is no unemployment.

We specify further that agents face the choice of how hard to work when young and when to retire when old. The former is an intensive labor supply decision, $L$, while the extensive labor supply margin reflects a discrete participation decision of whether to work at all. The retirement date is denoted by $x$ and corresponds to the share of the overall old-age period spent in active employment. First- and second-period budgets (normalized by the fixed wage rate of unity) correspond to:

$$
c_{1}=(1-\tau) L-s, \quad c_{2}=x \cdot(1-\tau)+(1-x) \cdot p+R s,
$$

where $s$ is savings, $\tau$ is the statutory contribution rate to the pension system, $p$ represents pension earnings, and $R(\equiv 1+r)$ is the (constant) interest factor. During the second period of life, the agent continues working for a share $x$ of the entire period and retires for the remaining part $1-x$. We refer to the variable $x$ as the retirement date. Upon retirement, wage earnings are replaced by pension income. To further simplify, we assume that labor supply in the second period is fixed.

Life-time utility of an agent is of the usual intertemporally separable form. To keep the analysis simple, we assume preferences are additively separable between consumption and work effort within each period and thereby exclude income effects on labor supply. Since our analysis is concerned with the effects of pension reform on labor market behavior rather than on savings, we also assume preferences are linear in consumption. In consequence, agents care only about the present value but not the timing of consumption. With present and future consumption being perfectly substitutable, the interest rate must be equal to the rate of time preference and is, thus, exogenous:

$$
V=c_{1}-\varphi(L)+\frac{1}{R} \cdot\left[c_{2}-\gamma \phi(x)\right] .
$$

\footnotetext{
${ }^{4}$ Our framework abstracts from a human capital accumulation decision. See Lau and Poutvaara (2006) for an analysis of the interactions between social security and human capital.
} 
The parameter $\gamma$ scales the preference for early vs late retirement. Disutility of work effort $\varphi(L)$ when young and of continued employment $\phi(x)$ during old age are convex increasing, i.e., the derivatives $\varphi^{\prime}, \varphi^{\prime \prime}, \phi^{\prime}$, and $\phi^{\prime \prime}$ are all positive. ${ }^{5}$

Since it is crucial in analyzing alternative pension policies, we must describe in detail the factors influencing pension earnings, $p$. They are given by:

$$
p=m(x)\left[\tau L \cdot R^{p}+\tau x\right]+b,
$$

where $b$ is a "flat" pension payment independent of contributions. The pension system might pay interest on contributions, which is reflected by the factor $R^{p}$. The key relationship in our analysis is the conversion factor $m(x)$ that scales contributions from past earnings into a pension entitlement. It reflects the taxbenefit link that can be actuarially adjusted depending on old-age labor market participation, or retirement, decision $x$. The specification Eq. 3 encompasses several distinct pension regimes: (1) a Beveridge-type system $(m(x)=0)$ in which "flat" old-age earnings are independent of contributions, $p=b ;(2)$ a Bismarckian PAYG system that incorporates a constant tax-benefit link, $m(x)=m_{0}>0$, with $b=0$ and $R^{p}=1$. If the conversion factor does $n o t$ increase in the retirement date, the system remains unfair in the sense that pension adjustment does not reflect the length of the remaining life-time, equal to $1-x$; (3) a modified PAYG system with an actuarial adjustment of pensions conditional on the retirement date ("Gruber-Wise" incentives), $m^{\prime}(x)>0$; and (4) a fully funded system in which contributions earn the market rate of interest, $R^{p}=R$, and pension earnings are adjusted to take into account the length of the retirement period so that $m(x)=1 /(1-x){ }^{6}$

To model the implications of a number of structural pension reforms, we assume that the pension conversion factor reflecting the tax-benefit link, $m(x)$, takes the specification:

$$
m=m(x)=\frac{\alpha}{1-x}+m_{0}, \quad \alpha>0,
$$

which embeds an actuarial adjustment component $\alpha /(1-x)$ and a constant term $m_{0}$ scaling the tax-benefit link. Actuarial adjustment is partial if $0<$ $\alpha<1$ and complete if $\alpha=1$. Given Eqs. 3 and 4, the Bismarck-type pension equals $p=m_{0} \tau[L+x]$, while its fully capital funded counterpart is $p=$ $(1-x)^{-1} \tau[L \cdot R+x]$, with $b=m_{0}=0$. Substituting the pension formula of the funded system into the budget identities of the agent shows that lifetime wealth is independent of the parameters of the pension system, i.e., $c_{1}+c_{2} / R=L+x / R$. The fully funded system provides a perfect substitute for private savings and is fully neutral in this framework.

\footnotetext{
${ }^{5}$ Appendix $\mathrm{C}$ describes how our specification of preferences is related to standard assumptions in the literature that are found in Cigno (2008) and Fenge and Pestieau (2005), among others.

${ }^{6}$ As Feldstein (2005a) points out, the absence of a tax-benefit link implies that an agent's contributions represent a 100\% tax rate. Regarding PAYG systems with a tax-benefit link, Fenge and Werding (2004) provide evidence that approximately 50\% of contributions in Germany are effectively a tax.
} 
The pure funded system eliminates the effective tax rates on both the intensive labor supply of prime age workers and the participation decision of older workers (see below, Eqs. 6 and 12). The analysis here also shows that three conditions must be fulfilled for complete actuarial fairness in both dimensions of labor supply: (1) past contributions must earn a rate of return equal to the return on private savings, $R^{p}=R$; (2) the conversion factor fully reflects expected remaining life-time, $m=1 /(1-x)$ and $m_{0}=0$; and (3) there is no lump-sum, flat pension component, $b=0$. A violation of one of these conditions results in a positive effective pension tax on one of the two margins of labor supply, as the discussion of effective tax rates below will show.

Substituting the budget identities into the value function $V$ yields the problem:

$$
V=\max _{L, x}(1-\tau) L-\varphi(L)+\frac{1}{R}[x(1-\tau)+(1-x) p-\gamma \phi(x)],
$$

subject to $p$ determined by Eqs. 3 and 4. The optimality condition with respect to a young worker's labor supply decision is:

$$
\varphi^{\prime}(L)=\left(1-\tau_{L}\right), \quad \tau_{L}=\tau \cdot\left[1-(1-x) m \cdot R^{p} / R\right]<\tau,
$$

where $\tau_{L}$ is the implicit tax rate on first-period employment $L$ in the sense of Feldstein and Samwick (1992). It will be discussed more fully below. The participation, or retirement, decision of an older worker is governed by:

$$
\gamma \phi^{\prime}(x)=(1-\tau)-p+(1-x) \frac{\partial p}{\partial x},
$$

where the derivative in the last term:

$$
\frac{\partial p}{\partial x}=\tau \cdot\left[m^{\prime} \cdot\left(L R^{p}+x\right)+m\right],
$$

reflects the effect on pension earnings of choosing a longer working life $x$. Since Eqs. 6-8, together with the economy's resource constraints, determine the equilibrium response of workers to pension policy, it is important to analyze these conditions in more detail.

\subsection{Intensive labor supply}

Observe in Eq. 6 that the effective tax $\tau_{L}$ on intensive labor supply is less than the statutory rate $\tau$. In a system with a tax-benefit link, pensions are assessed on the basis of past earnings. Greater work effort by the young raises not only current income but also leads to higher retirement income when old. This means that not all of the contribution rate is perceived as a "pure" tax. Agents foresee an individual return in terms of higher pension entitlements accruing in the retirement period $1-x$. Moreover, the simple relationship in Eq. 6 contains the essential insights regarding intensive labor supply.

First, contributions earn no interest $\left(R^{p}=1\right)$ under a PAYG system. Future benefits are discounted by the market interest rate. The younger an agent, the more distant future pensions are, and, hence, the larger the discounting is. For 
this reason, empirical calculations, such as in Feldstein and Samwick (1992) or Fenge and Werding (2004), show that implicit tax rates tend to be rather high for younger workers and fall as retirement approaches. Second, if the retirement age $x$ increases, pensions are consumed over a shorter remaining retirement period. If the conversion factor is not increased simultaneously, a higher retirement age raises implicit tax rates on the young and leads to a larger distortion of intensive labor supply. Third, the formula nests the extreme cases of flat PAYG (Beveridge) and fully funded systems. In a flat system without any tax-benefit link, $m=0$, pension contributions are effectively taxed at the statutory rate, $\tau_{L}=\tau$. In contrast, $\tau_{L}$ is zero under the fully funded system. The fully funded system pays full interest on contributions, $R^{p}=R$, and also adjusts pension size in an actuarially fair way, $m=(1-x)^{-1}$, to take account of the length of the remaining retirement period. Note that a GruberWise adjustment for late retirement adjusts the conversion factor in a similar way and, hence, reduces the implicit tax on young workers. However, since contributions earn no interest, this adjustment is not sufficient to entirely eliminate the implicit tax on the young.

Calculating the relative change of intensive labor supply in Eq. 6 yields:

$$
\hat{L}=-\sigma \cdot \hat{\tau}_{L}, \quad \sigma \equiv \varphi^{\prime} /\left(L \varphi^{\prime \prime}\right)>0,
$$

where $\hat{\tau}_{L} \equiv d \tau_{L} /\left(1-\tau_{L}\right)$ and $\sigma$ is the (constant) net wage elasticity of work effort. ${ }^{7}$ Clearly, a rise in the implicit tax rate $\tau_{L}$ reduces first-period labor supply. As argued above, the implicit tax rate depends, through the tax-benefit link, on the retirement date $x$. We now set $R^{P}=1$, an assumption we employ in the rest of the paper, and use $m-(1-x) m^{\prime}=m_{0}$ from Eq. 4 to obtain:

$$
\hat{\tau}_{L}=\frac{\tau m_{0} x}{\left(1-\tau_{L}\right) R} \cdot \hat{x} .
$$

Consequently, intensive labor supply of young workers is linked to the retirement behavior—or extensive labor supply—of old agents, according to:

$$
L^{\prime}(x)=\frac{d L}{d \tau_{L}} \cdot \frac{d \tau_{L}}{d x}=-\Psi<0, \quad \Psi \equiv \frac{\sigma L}{1-\tau_{L}} \cdot \frac{m_{0} \tau}{R}>0,
$$

reflecting the fact that longer working life raises the effective tax rate on young workers.

\subsection{Retirement decision}

We assume that continued employment of older workers leads to progressively increasing disutility of labor market participation, $\phi^{\prime \prime}>0$. The retirement decision in Eq. 7 balances the marginal cost of labor market participation $\gamma \phi^{\prime}(x)$ against the income differential between wages and pension earnings

\footnotetext{
${ }^{7}$ For a variable $y, \hat{y}$ represents the relative change $\hat{y} \equiv d y / y$. The change in the tax rate is relative to the tax factor, $\hat{\tau} \equiv d \tau /(1-\tau)$.
} 
that becomes available by marginally postponing retirement. The impact of the pension system on retirement behavior can be summarized by a single effective tax measure that is obtained upon rewriting Eq. 7 as:

$$
\gamma \phi^{\prime}(x)=\left(1-\tau_{R}\right), \quad \tau_{R} \equiv \tau+p-(1-x) \frac{\partial p}{\partial x},
$$

where $\tau_{R}$ is a participation tax rate, often called the implicit retirement tax. ${ }^{8}$

It summarizes all fiscal incentives and disincentives for retirement in a single metric, which consists of: (1) the wage taxes paid on a worker's salary, (2) the pension foregone with continued employment, and (3) the pension increase over the remaining retirement period if the system incorporates actuarial adjustment. The "implicit retirement tax" discussed in pension economics literature is parallel to the participation tax analyzed in the literature on extensive labor supply such as Saez (2002), Immervoll et al. (2007), and Kleven and Kreiner (2006). Note, in particular, how an actuarial adjustment of pensions in the sense of Gruber and Wise $(\partial p / \partial x>0)$ lowers the effective retirement tax. This adjustment compensates for prolonged contribution payments due to continued work and a shorter retirement period and, hence, a shorter period of pension take-up. In a Beveridge-type system without a tax-benefit link $(m=0)$ and, thus, with a flat pension, the retirement tax would equal $\tau_{R}=\tau+p$, i.e., the sum of the contribution rate $\tau$ plus the (normalized) replacement rate $p$. Finally, the retirement tax is zero $\left(\tau_{R}=0\right)$ in the fully funded system. In this case, the pension is increased in an actuarially fair way when retirement is postponed in order to compensate for the extra contributions and foregone pensions over the longer contribution period and the shorter duration of benefits.

To measure how retirement behavior responds to fiscal incentives, we calculate the log-derivative of Eq. 12:

$$
\hat{x}=-\eta \cdot\left(\hat{\tau}_{R}+\hat{\gamma}\right), \quad \eta \equiv \frac{\phi^{\prime}}{x \phi^{\prime \prime}}>0,
$$

where the parameter $\eta$ is the elasticity of labor market participation. Participation declines and retirement occurs earlier if the effective tax rate $\tau_{R}$ increases. A larger disutility $\gamma$ from continued work reflects exogenous socioeconomic factors leading to a "trend" to earlier retirement, a case that will be explored in greater detail below.

Since the participation tax rate $\tau_{R}$ is a function of $x$, it is important to explore its properties further. First, it is convenient to express pension earnings in Eq. 3 in terms of the pension assessment base, which we denote by $z$ :

$$
p=m(x) \tau z(x)+b, \quad z(x)=L(x)+x .
$$

\footnotetext{
${ }^{8}$ Sheshinski (1978), among others, show in a formal model that a pension system can encourage late retirement if benefits increase in the retirement date. Labor supply of active workers was assumed to be fixed. A major theme of this paper is the interaction of retirement incentives with labor market behavior of prime age workers.
} 
With an earnings-linked pension formula, such as Eq. 14, pension entitlements become sensitive to the retirement date via three channels: (1) postponing retirement augments the pension assessment base by prolonging the active working period in old age, which translates into a higher pension depending on the conversion factor $m$; (2) postponing retirement increases, however, (see Eq. 10), the implicit tax rate on young workers, thereby discouraging intensive labor supply $L$ and shrinking the assessment base, which leads to smaller pensions; and (3) the system can directly encourage postponed retirement by raising the conversion factor $m$. For convenience, we employ primes to denote the partial derivatives of $m, z$, and $p$ with respect to $x$. The first two effects are summarized by $z^{\prime}>0$, which is positive if the intensive labor supply elasticity is not too large. ${ }^{9}$ The last effect depends on $m^{\prime} \geq 0$ and is clearly zero if the system provides no actuarial adjustment with respect to the choice of $x$. The sensitivity of pension size with respect to the chosen retirement date is thus:

$$
p^{\prime}=\tau \cdot\left[z m^{\prime}+m z^{\prime}\right]>0, \quad p^{\prime \prime}=\tau \cdot\left[2 z^{\prime} m^{\prime}+z m^{\prime \prime}+m z^{\prime \prime}\right] .
$$

We next analyze the effect of an extended working life on the participation tax. Differentiating $\tau_{R}$ given in Eq. 12 with respect to $x$, substituting Eq. 15, and using $(1-x) m^{\prime \prime}=2 m^{\prime}$ and $m-(1-x) m^{\prime}=m_{0}$ from Eq. 4, we obtain:

$$
\frac{\partial \tau_{R}}{\partial x} \equiv \tau_{R}^{\prime}=\tau \cdot\left[2 m_{0} z^{\prime}-(1-x) m z^{\prime \prime}\right] \geq 0,
$$

where $z^{\prime \prime}=L^{\prime \prime}<0 .{ }^{10}$ Postponed retirement raises (respectively, leaves unaffected) the participation tax. If there is no tax-benefit link, the participation tax rate is independent of the retirement date. If the conversion factor remains fixed and excludes any actuarial adjustment $\left(m_{0}>0\right.$ and $\left.\alpha=0\right)$, then $z^{\prime}>$ $0>z^{\prime \prime}$, which implies a higher participation tax due to postponed retirement, $\tau_{R}^{\prime}>0$. If, instead, the conversion factor is actuarially adjusted to the retirement date $\left(m=\alpha /(1-x)\right.$ and $\left.m_{0}=0\right)$, the participation tax is also independent of the retirement date. In this case, with $(1-x) m=\alpha$, retirement behavior does not influence the implicit tax on the young, so that first-period labor supply remains unaffected and the assessment base satisfies $z^{\prime}=1$ and $z^{\prime \prime}=0$.

\subsection{Equilibrium}

Our model is very stylized with only three overlapping generations and two periods. The focus is on generation 1 that is young in period 1 and old in period 2. To close the model, we assume the existence of an initial old generation of pensioners (generation 0 ) coexisting in period 1 with the young generation 1.

\footnotetext{
${ }^{9}$ To guarantee $z^{\prime}=1+L^{\prime}>0$, we assume $\Psi<1$ (see Eq. 11 above), which holds for sufficiently small values of $m_{0}$ and $\sigma$.

${ }^{10}$ Observe that $z^{\prime \prime}$ is negative. Given the assumption $\sigma<1$, Eqs. 10 and 11 imply $z^{\prime \prime}=L^{\prime \prime}=-\frac{1-\sigma}{\sigma \cdot L}$. $\Psi^{2}<0$.
} 
We further assume a future generation of workers in period 2 that lives for one period and coexists with generation 1 when it is old. ${ }^{11}$ The upper index identifies generations 0 "old" and $f$ "future," while variables without an upper index refer to the active generation 1, which is the only generation living over the entire two-period life-cycle. The only activity of the old generation 0 is to consume PAYG pensions that must be paid from the contributions of generation 1:

$$
c^{0}=p^{0}, \quad V^{0}=c^{0} / R .
$$

Since our focus is on the behavior of generation 1, we assume away labor market participation on the part of generation 0 . In other words, it is fully retired. The counterpart of generation 0 is a "future" generation, which lives for only one period and inelastically supplies one efficiency unit of labor. In period 2, both the young and the old of generation 1 receive a competitive wage $W=1$. Members of the future generation are assumed to be fully employed. Their sole activity is to consume fixed labor earnings after paying contributions to finance pensions of the then old generation 1. This reflects the fact that any PAYG pension system basically redistributes from future to present generations:

$$
V^{f}=c^{f}=(1-\tau) .
$$

The budgets of the PAYG system in periods 1 and 2 are:

$$
p^{0}=\tau L, \quad(1-x) p=\tau \cdot(1+x),
$$

where we again normalize the wage rate of unity. In the second period, $\tau$ represents the contributions from the future generation and $\tau x$ from the active part of the old of generation 1 . Consequently, the pension is partly funded by an intergenerational transfer. ${ }^{12}$

Given a Ricardian technology, output in period 1 is simply $L$. Substituting Eq. 19 into the budget identity Eq. 1 and using Eq. 17 yields the GDP identity $L=c_{1}+c^{0}+s$ for the first period. Output is spent on consumption by young and old agents and on private investment $s .{ }^{13}$ In the second period, new output

\footnotetext{
${ }^{11}$ Clearly, our model does not incorporate demographic effects such as ageing. Recent work that considers the implications of ageing on pension systems includes Ono (2003) and Lacomba and Lagos (2006). Ono (2003) shows that debt-funded social security systems can lead to dynamic inefficiencies and multiple equilibria, while Lacomba and Lagos (2006) focus on the effects of ageing on the optimal statutory retirement age. They find the effects depend on whether the pension system is a defined contribution or defined benefit scheme.

${ }^{12}$ In the funded system, the budget would apply to each person separately, making the generational account zero and eliminating intergenerational redistribution: $(1-x) p=\tau \cdot(L R+x)$.

${ }^{13}$ The investment technology is linear in the coefficient $R$, and present and future consumption are perfect substitutes. Since it is not required for the present purposes, we intentionally leave savings and investment undetermined in our model. Alternatively, we can impose a small open economy assumption.
} 
Fig. 1 Early retirement

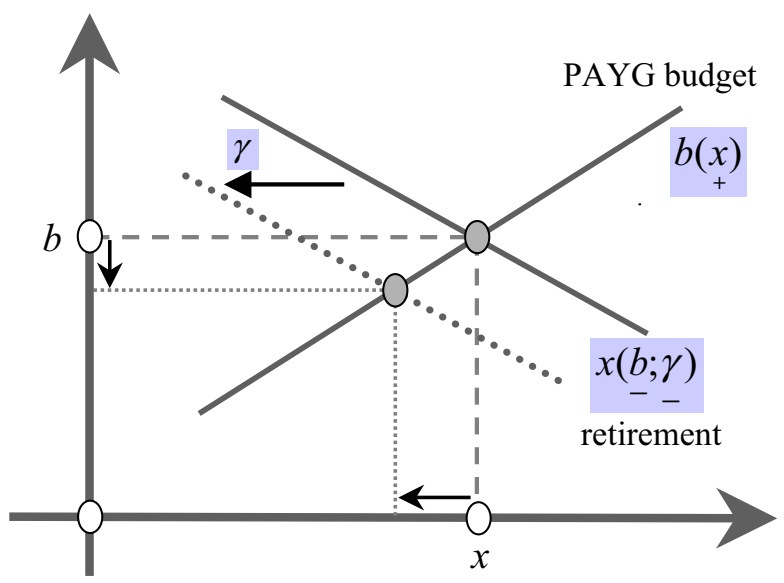

$1+x$ is produced by generation 2 and by the still active part of generation 1 . To obtain output market clearing, we aggregate Eqs. 1 and 18 and substitute for Eq. 19 to yield: $c_{2}+c^{f}=1+x+R s$. Second-period GDP equals new output plus the yield on first-period investment. Since the world ends thereafter, output is fully consumed.

\subsection{Early retirement}

The equilibrium of the economy is fully characterized by a retirement age $x$ and a "flat,"lump-sum pension $b$ that simultaneously satisfy the extensive labor market condition (Eq. 12) and the budget constraint (Eq. 19). ${ }^{14}$ The linearized versions of these two conditions, which take into account the intensive labor supply choice in Eq. 11, are derived in part A of the Appendix-see Eqs. 50 and 52-and are illustrated in the $x, b$ plane of Fig. 1. The retirement condition describes a downward-sloping relationship, since a higher flat pension makes early retirement more attractive, which reduces the retirement age. In contrast, the budget condition is upward-sloping, since the PAYG system can support a greater level of flat pensions over the remaining retirement period only if the working life of agents is extended. The intersection of the two lines determines the equilibrium values of $x$ and $b$.

Before proceeding with an analysis of parametric pension reform, we first illustrate how an exogenous trend toward early retirement alters labor market choices on both margins and affects the pension system. An early retirement "trend" results from exogenous socioeconomic factors and is modeled by

\footnotetext{
${ }^{14}$ Our subsequent analysis refers, then, to a defined contribution system in which the contribution rate is fixed and pension size must ultimately be adjusted to guarantee the system's solvency.
} 
an increase in the preference parameter $\gamma$ that determines the disutility of old-age labor market participation. Holding the pension parameters fixed, Eqs. 50 and 52 then simplify to:

$$
\hat{x}=-\frac{\eta}{1+\eta \varepsilon} \cdot \frac{d b}{1-\tau_{R}}-\frac{\eta}{1+\eta \varepsilon} \cdot \hat{\gamma}, \quad d b=\frac{\tau_{R} x}{1-x} \cdot \hat{x},
$$

where $\varepsilon \equiv \tau_{R}^{\prime} x /\left(1-\tau_{R}\right)$ is the elasticity of the implicit participation tax. Solving Eq. 20 for $\hat{x}$ and $d b$, we find the following equilibrium responses:

$$
\begin{aligned}
\hat{x} & =-\frac{\eta}{1+\eta \varepsilon} \cdot \frac{1}{\nabla} \cdot \hat{\gamma}<0, \\
d b & =-\frac{\tau_{R} x}{1-x} \cdot \frac{\eta}{1+\eta \varepsilon} \cdot \frac{1}{\nabla} \cdot \hat{\gamma}<0, \\
\nabla & \equiv 1+\frac{\tau_{R}}{1-\tau_{R}} \cdot \frac{\eta}{1+\eta \varepsilon} \cdot \frac{x}{1-x}>0 .
\end{aligned}
$$

Not surprisingly, a preference shift toward early retirement reduces participation in the old-age labor market, $\hat{x}<0$. Furthermore, it requires budget consolidation to keep the system sustainable and, thus, leads to pension cuts, $d b<0$, as Fig. 1 shows. ${ }^{15}$ Interestingly, early retirement also reduces the effective retirement tax in equilibrium:

$$
\hat{\tau}_{R}=\varepsilon \cdot \hat{x}+\frac{d b}{1-\tau_{R}}<0 .
$$

The result is, again, quite intuitive. Not only does the participation tax decline when the flat component $b$ of pensions fall, it also declines with an earlier retirement date $x$.

The effect of $\hat{x}$ on the participation tax depends on $\varepsilon \equiv \tau_{R}^{\prime} x /\left(1-\tau_{R}\right)$ and is present only if the earnings-linked pension is relatively insensitive to retirement behavior. The conversion factor then depends largely on the fixed term $m_{0}$ and does not compensate sufficiently in terms of pension supplements $p^{\prime}$ received for the prolonged contribution and shorter retirement periods. This, in turn, magnifies the imbalance between the marginal returns and costs of postponing retirement, implying that the participation tax increases with the retirement date, i.e., $\tau_{R}^{\prime}>0$. Correspondingly, the participation tax declines when agents retire earlier. The reduction in $\tau_{R}$ tends, of course, to encourage later retirement, but cannot offset the trend to early retirement from the original preference shock.

\footnotetext{
${ }^{15}$ Observe, however, that an explicit consolidation is necessary only when the system is actuarially unfair in the sense of Gruber and Wise and features a positive $\tau_{R}$. An actuarially fair system with $\tau_{R}=0$ consolidates automatically, since earlier retirement reduces the conversion factor, reflecting the resulting longer retirement and shorter contribution periods.
} 
Irrespective of whether the system includes an actuarially fair adjustment for changes in the length of the retirement period, we find, interestingly, that early retirement raises intensive labor supply of younger workers. Using Eqs. 9-11, we obtain:

$$
\hat{\tau}_{L}=\frac{\tau m_{0} x}{\left(1-\tau_{L}\right) R} \cdot \hat{x}<0 \Rightarrow \hat{L}=-\sigma \cdot \hat{\tau}_{L}>0 .
$$

The intuition is best understood by reference to the Bismarckian system with a fixed conversion factor, $m=m_{0}$. When the retirement date is moved forward, contribution payments yield pension gains earlier in life and over a longer retirement period. The implicit tax defined in Eq. 6 thus falls, stimulating intensive labor supply. Moreover, even if the conversion factor $m$ includes an actuarial component, the implicit tax on the young falls, as long as the reduction in the conversion factor is insufficiently great. ${ }^{16}$

\section{Efficiency of public pensions}

\subsection{Welfare measure}

To judge the efficiency of pension systems, we need a consistent welfare metric. To this end, we use the PAYG budgets in Eq. 19 to restate indirect utility of all three generations:

$$
\begin{aligned}
V^{0} & =p^{0} / R=\tau L / R, \\
V & =(1-\tau) L-\varphi(L)+[x(1-\tau)+(1-x) p-\gamma \phi(x)] / R, \\
V^{f} & =(1-\tau)=(1-\tau)+\tau \cdot(1+x)-(1-x) p .
\end{aligned}
$$

The utilitarian social welfare function, also employed by Calvo and Obstfeld (1988), is the discounted sum of individual utilities:

$$
\Phi=R V^{0}+V+V^{f} / R=L-\varphi(L)+\frac{1}{R}[1+x-\gamma \phi(x)],
$$

where the second equality follows upon substituting Eq. 19. This welfare function exclusively reflects economic efficiency and does not incorporate distributional concerns. ${ }^{17}$

Given that intensive and extensive labor supply are the only behavioral margins, the welfare effects of pension policy must be proportional to changes

\footnotetext{
${ }^{16}$ The implicit tax rate on intensive labor supply is independent of retirement behavior only if the conversion factor depends exclusively on retirement duration, i.e., $m_{0}=0$ and $m=\alpha /(1-x)$ imply a constant $\tau_{L}=\tau(1-\alpha / R)$.

${ }^{17}$ This is less restrictive than it seems. As in Keuschnigg (1994), we can analytically separate efficiency from intergenerational redistribution. In Demmel and Keuschnigg (2000), this decomposition is used to construct an (ex ante) Pareto-improving reform.
} 
in $x$ and $L$. Taking the differential of Eq. 25, substituting for the private choices of work effort and retirement in Eqs. 6 and 12, and letting $W=1$, we find:

$$
d \Phi=\left[1-\varphi^{\prime}(L)\right] \cdot d L+\frac{1-\gamma \phi^{\prime}(x)}{R} \cdot d x=\tau_{L} \cdot d L+\frac{\tau_{R}}{R} \cdot d x .
$$

Note that the coefficients on $d L$ and $d x$ for the change in welfare $d \Phi$ reflect the differences between the social and private returns of a marginal increase in hours worked, 1 vs $1-\tau_{L}$, and in the retirement date, 1 vs $1-\tau_{R}$. Substituting for $\hat{L}$ and $\hat{x}$ from Eqs. 9 and 13 (and holding $\hat{\gamma}=0$ ), the welfare effects become:

$$
d \Phi=\tau_{L} L \cdot \hat{L}+\frac{\tau_{R} x}{R} \cdot \hat{x}=-\tau_{L} \cdot \sigma L \cdot \hat{\tau}_{L}-\tau_{R} \cdot \eta \frac{x}{R} \cdot \hat{\tau}_{R} .
$$

The welfare impact of any behavioral changes induced by pension reform is, to the first order, proportional to the effective tax rates on work effort and old-age participation. The pension system is the only source of inefficiency in our simple framework. If it were absent, allocation would be Pareto optimal. Introducing small contributions and pension entitlements would, to the first order, entail a zero marginal welfare impact.

\subsection{Higher statutory tax rate}

To study the labor market and efficiency effects of PAYG pensions, we first consider an increase in the statutory contribution rate $\tau$. Since the analysis of the general case is quite complex, we concentrate on three specific scenarios to bring out the main message of our analysis. First, we consider complete actuarial fairness in the sense that the system adjusts the earnings-linked pension to take into account the length of the retirement period. This case emphasizes that, while actuarial adjustment in the sense of Gruber and Wise eliminates the distortion in the retirement date, it is insufficient to ensure complete labor market neutrality of the pension system. The second scenario assumes a fixed labor supply of younger workers and incomplete actuarial adjustment in the pension formula. Here, we show that a Bismarckian system with a fixed tax-benefit link mitigates, but does not remove, the distortion in the retirement decision. The third scenario entirely eliminates any tax-benefit link and considers the labor market impact of flat pensions unrelated to past earnings. The succeeding section will then characterize the excess burden when the labor market is distorted both on the intensive and extensive margins.

Actuarial fairness A number of countries have reformed their earnings-linked PAYG systems by including pension supplements in the sense of Gruber and Wise to compensate for postponed retirement. If the pension rule is made sufficiently sensitive to the choice of retirement date and adjusts the conversion factor in an actuarially fair way to reflect the longer contribution period and the shorter length of the remaining retirement period, all distortions with regard to labor market participation of older people can be eliminated. In our simple framework, this calls for a conversion factor in Eq. 4 equal 
to $m(x)=1 /(1-x)$ with $\alpha=1$ and $m_{0}=0$. In this case, $(1-x) m^{\prime}=m$. Since it implies $\Psi=0$, we find from Eq. 57 in the Appendix that the direct effect of the contribution rate, for any given retirement date $x$, on the participation tax rate is zero, $\partial \tau_{R} / \partial \tau=0$. To understand why, one must note that the fair conversion factor $(1-x) m=1$ eliminates any sensitivity of the implicit tax rate $\tau_{L}$ with respect to the retirement date so that intensive labor supply of younger workers becomes independent of the retirement decision. Consequently, the sensitivity of the assessment base $z=L+x$ with respect to retirement reduces to the retirement margin only, $z^{\prime}=1$ (which obviously implies $\left.\partial z^{\prime} / \partial \tau=0\right)$. The increase in the assessment base $z^{\prime}$ on account of a longer contribution period and any direct impact $\partial z / \partial \tau$ of the first-period labor supply response on the assessment base are fully translated into an adjustment of the pension size so that the effective retirement tax is unaffected. Using, in Eq. 55, the fact that a fair system is characterized by $(1-x) m^{\prime}=m$, $(1-x) m=z^{\prime}=1$, and $\partial z^{\prime} / \partial \tau=0$, and substituting into Eq. 53, indeed proves $\partial \tau_{R} / \partial \tau=0$.

However, this does not mean that such a system does not influence the retirement date. The level of the participation tax rate is positive as long as there is a flat, lump-sum pension, $\tau_{R}=b$. To see this, note the pension formula $p=m \tau z+b$, with $p^{\prime}=\tau\left[m^{\prime} z+m z^{\prime}\right]$. Using $z^{\prime}=1,(1-x) m^{\prime}=m$, and $(1-x) m=1$ in Eq. 12 confirms the result. If the higher contribution rate raises extra revenues beyond what is needed to pay for the higher earningslinked pensions, the flat pension $b$ becomes more generous, which, in turn, raises the participation tax rate and leads to earlier retirement.

The extent of the tax revenue increase depends, of course, also on the resulting intensive labor supply response. Even if the system is actuarially fair with respect to the retirement date, the implicit tax rate on young workers is still positive, $\tau_{L}=\tau \cdot(1-1 / R)>0$, since an unfunded system does not pay interest on accumulated contributions. An increase in the statutory contribution rate thus raises the effective tax component on contributions and discourages intensive labor supply. To verify these statements, we solve the system stated in Eqs. 50 and 52. Since $z^{\prime}=1$ and $m_{0}=z^{\prime \prime}=0$ in the present scenario, we have $\tau_{R}^{\prime}=0$ in Eq. 16, which eliminates the elasticity $\varepsilon$ from the resulting expressions. Together with $\partial \tau_{R} / \partial \tau=0$, the system reduces to:

$$
\hat{x}=-\frac{\eta}{1-\tau_{R}} \cdot d b, \quad d b=\frac{\tau_{R} x}{1-x} \cdot \hat{x}+\left[\frac{b}{\tau}+\frac{\tau_{L}}{1-\tau_{L}} \sigma m L\right] \cdot d \tau,
$$

where the terms in square brackets replace the one in Eq. 52. To see this, note that the PAYG budget in Eq. 19 and the pension formula imply $\frac{1+x}{1-x}=$ $p / \tau=m z+b / \tau$. Using this expression and combining with Eqs. 54-55 yields the square brackets in Eq. 28.

The resulting solution can be illustrated using Fig. 1. In contrast to the case of a trend toward early retirement, the budget line shifts up in response to the rise in $\tau$, while the position of the retirement locus remains unchanged. 
Consequently, agents retire earlier, and the system affords a more generous flat pension component. The comparative static solution, using Eq. 28, corresponds to: ${ }^{18}$

$$
\begin{aligned}
\hat{x} & =-\frac{\eta}{1-\tau_{R}} \frac{1}{\nabla}\left[\frac{b}{\tau}+\frac{\tau_{L}}{1-\tau_{L}} \sigma m L\right] \cdot d \tau<0, \\
d b & =\frac{1}{\nabla}\left[\frac{b}{\tau}+\frac{\tau_{L}}{1-\tau_{L}} \sigma m L\right] \cdot d \tau>0, \\
\nabla & =1+\frac{\tau_{R}}{1-\tau_{R}} \frac{x}{1-x} \eta .
\end{aligned}
$$

We have thus seen that expanding the system with an actuarially fair adjustment of the conversion factor not only pays for a more generous earnings-linked pension but also for a higher flat pension. The latter effect raises the participation tax rate and results in early retirement. In addition, the implicit tax rate on the young $\tau_{L}=\tau \cdot(1-1 / R)$ increases because the adjustment of the conversion factor cannot undo the fact that contributions in an unfunded system pay no interest and, thus, partly represent a tax on the young that distorts intensive labor supply, $\hat{L}=-\sigma \cdot \hat{\tau}_{L}<0$. According to Eq. 27, aggregate welfare declines on both margins. The welfare loss would be zero on the extensive retirement margin if, in the initial equilibrium, the flat pension and, thus, the participation tax rate were zero: $\tau_{R}=b=0$.

Fixed labor supply of young workers When labor supply is completely insensitive to variations in effective wages $(\sigma=0)$, the pension assessment base $z=L+x$ depends only on changes in the retirement date $\left(z^{\prime}=1\right)$, so that $\partial z / \partial \tau=\partial z^{\prime} / \partial \tau=0$. In evaluating the impact of the statutory contribution rate on the participation tax rate, we find from Eqs. 53-57

$$
\partial \tau_{R} / \partial \tau=1-\alpha+m_{0}[z-(1-x)] \geq 0 .
$$

We assume in this scenario that the conversion factor $m$ is "imperfectly" fairas it in fact is in most countries-and allow for arbitrary parameter values $\alpha \in$ $[0,1]$ and $m_{0} \cdot{ }^{19}$ If the conversion factor were fair, $\alpha=1$ and $m_{0}=0$, a higher contribution rate would not affect the participation tax rate.

We now solve for the equilibrium impact of the policy change. With fixed labor supply, $\partial p / \partial \tau=m z$. The PAYG budget constraint Eq. 19 implies $(1+x) /(1-x)=p / \tau$ while the pension formula is rearranged to yield $m z=(p-b) / \tau$. Substituting this expression into the term square brackets in Eq. 52, the equilibrium system Eqs. 50 and 52 simplifies to $\hat{x}=$

\footnotetext{
${ }^{18}$ Table 1 gives the qualitative responses of $\left(\hat{\tau}_{R}, \hat{x}, \hat{\tau}_{L}, \hat{L}, d b\right)$ to an increase in $\tau$ under actuarial fairness, together with the responses to the policy scenarios considered in Section 4.

${ }^{19}$ With $z^{\prime}=1$, Eqs. 12 and 15 imply $\tau_{R}=b+\tau\left[1-\alpha+m_{0}(z-(1-x))\right]$. The second term shows how the earnings-linked pension leads to a positive participation tax rate. If it were positive and, thus, unfair initially, then the participation tax will increase with a higher contribution rate.
} 
Table 1 Qualitative responses under alternative policy reforms

\begin{tabular}{lllll}
\hline & $d \tau>0$ & $d m_{0}>0$ & $d \alpha>0$ & $d \alpha_{\mid m=\bar{m}}>0$ \\
\hline$\hat{\tau}_{R}$ & $(+)$ & $(-)$ & $(-)$ & $(-)$ \\
$\hat{x}$ & $(-)$ & $(+)$ & $(+)$ & $(+)$ \\
$\hat{\tau}_{L}$ & $(+)$ & $(-)$ & $(-)$ & 0 \\
$\hat{L}$ & $(-)$ & $(+)$ & $(+)$ & 0 \\
$d b$ & $(+)$ & $(-)$ & $(-)$ & $(+)$ \\
\hline
\end{tabular}

$-\frac{\eta}{1+\eta \varepsilon} \frac{1}{1-\tau_{R}}\left[d b+\frac{\partial \tau_{R}}{\partial \tau} \cdot d \tau\right]$ and $d b=\frac{\tau_{R} x}{1-x} \cdot \hat{x}+\frac{b}{\tau} \cdot d \tau$. Noting the definition of $\nabla$ in Eq. 21, the corresponding solution is

$$
\begin{aligned}
\hat{x} & =-\frac{1}{1-\tau_{R}} \frac{\eta}{1+\eta \varepsilon} \frac{1}{\nabla}\left(\frac{b}{\tau}+\frac{\partial \tau_{R}}{\partial \tau}\right) \cdot d \tau<0, \\
d b & =-\frac{1}{\nabla}\left[\frac{\tau_{R}}{1-\tau_{R}} \frac{x}{1-x} \frac{\eta}{1+\eta \varepsilon} \frac{\partial \tau_{R}}{\partial \tau}-\frac{b}{\tau}\right] \cdot d \tau .
\end{aligned}
$$

The interpretation is of Eq. 31 straightforward. If the system is unfair with respect to the length of remaining retirement, as in the standard Bismarckian system with a fixed tax-benefit link $m_{0}$, the agent loses when retiring an instant later. The net effect of the extra contribution plus pension foregone minus the present value of the increase in future pensions reflects a positive participation tax. The loss on the extensive margin induces agents to retire earlier, thereby worsening the system's budgetary position. Consequently, the retirement date declines and the flat pension is reduced to keep the system sustainable (if $b$ is not too large initially). As a check on consistency, a fair system would involve $p=m \tau z$ with $b=0$ and $m=1 /(1-x)$, implying $\partial \tau_{R} / \partial \tau=0$, as argued above. There would then be no effect on the retirement date. ${ }^{20}$ Given the impact on retirement, the implication for economic efficiency in Eq. 27 is also clear. In sum, with a positive participation tax, retirement already occurs inefficiently early, so that an expansion of the system can only reinforce this distortion and lead to further efficiency losses.

Flat pensions If pensions are lump-sum from an individual's perspective and completely unrelated to past earnings, then labor market distortions are at their highest. The absence of a tax-benefit link is given by $\alpha=m_{0}=m=0$, reducing the pension formula to $p=b$. The effective tax rates on the intensive labor supply of younger workers and on the participation of their older counterparts are $\tau_{L}=\tau$ and $\tau_{R}=\tau+p$, respectively. Clearly, the participation tax rate is independent of the retirement date, implying $\tau_{R}^{\prime}=\varepsilon=0$. The absence of a tax-benefit link also implies $\partial p / \partial \tau=0$ and, of course, $\partial \tau_{R} / \partial \tau=1$. In

\footnotetext{
${ }^{20}$ The system would still redistribute intergenerationally, an issue that we do not analyze here.
} 
this case, the system in Eqs. 50 and 52 reduces to $\hat{x}=-\frac{\eta}{1-\tau_{R}}[d b+d \tau]$ and $d b=\frac{\tau_{R} x}{1-x} \cdot \hat{x}+\frac{1+x}{1-x} \cdot d \tau$, yielding a solution

$$
\begin{aligned}
\hat{x} & =-\eta \cdot \hat{\tau}_{R}=-\eta \cdot\left[\frac{1+x}{1-x}+1\right] \cdot \frac{d \tau}{\nabla\left(1-\tau_{R}\right)}<0, \\
d b & =\left[\frac{1+x}{1-x}-\frac{\tau_{R}}{1-\tau_{R}} \frac{x}{1-x} \eta\right] \cdot \frac{d \tau}{\nabla}>0, \\
\nabla & \equiv 1+\frac{\tau_{R}}{1-\tau_{R}} \frac{x}{1-x} \eta>0 .
\end{aligned}
$$

An increased contribution rate in a system without a tax-benefit link leads to earlier retirement and more generous flat pensions. The pension level grows less than proportionally because earlier retirement erodes the tax base, depending on the magnitude of the participation distortion $\tau_{R}$ and the extensive elasticity $\eta$. The increase in the effective tax rate $\tau_{L}=\tau$ also reduces firstperiod labor supply and the welfare of young workers.

\subsection{Excess burden}

This subsection provides a sharp characterization of the efficiency loss from expanding a PAYG pension system without a tax-benefit link. The absence of a tax-benefit link and the assumption of intertemporally separable preferences imply that pension budgets and labor market behavior can be analyzed independently in each period without any spillover. Although special, this case allows for a particularly simple and illuminating characterization of the excess burden from lump-sum PAYG pensions. Intensive labor supply $L$ occurs in the first period and depends only on the first-period tax rate $\tau_{1}$, while retirement behavior refers to the second period and depends exclusively on the second period tax rate $\tau_{2}$. In this case, $\tau_{L}=\tau_{1}$ leads to an intensive labor supply response in the first period equal to $\hat{L}=-\sigma \cdot \hat{\tau}_{1}$. Substituting this together with Eq. 32 into Eq. 27 yields:

$$
d \Phi=-\frac{\tau_{L}}{1-\tau_{L}} \sigma L \cdot d \tau_{1}-\frac{\tau_{R}}{1-\tau_{R}} \eta \cdot \frac{2 x}{\nabla R(1-x)} \cdot d \tau_{2} .
$$

Clearly, a permanent increase in contribution financed flat pensions $\left(d \tau_{1}=\right.$ $d \tau_{2}$ ) reduces aggregate welfare on both the intensive and extensive margins of labor supply.

We now develop a metric to evaluate the marginal excess burden of a tax, which is defined as the marginal loss in welfare in percent of net tax revenue raised at the margin. Using the budget relationships in Eq. 19 for a flat pension system, we write the intertemporal budget constraint as:

$$
T \equiv \tau_{1} L+\frac{\left(\tau_{2}+p\right) \cdot x}{R}=p^{0}+\frac{p-\tau_{2}}{R} .
$$

In measuring the excess burden of a PAYG system, we must take care of the overall impact of the behavioral response on the public budget. Not only the 
tax $\tau_{2}$ but also the spending $p$ distorts labor market participation of older workers. A policy-induced trend to early retirement erodes the contribution tax base and also generates extra pension claims. For this reason, the change in contribution revenues would capture only a, perhaps relatively unimportant, part of the overall fiscal cost of early retirement. We thus need to consider the participation tax revenue in the second period, equal to $\left(\tau_{2}+p\right) x=\tau_{R} x$. It measures the total fiscal gain when labor market participation is increased from zero to $x$ and consists of contribution payments plus savings on pension spending. The meaning of this definition is also seen from the budget in Eq. 1, $C_{2}=R S+x+p-\tau_{R} x$. If there were no participation at all, pension spending would have been $p$. When retirement is postponed by $x$, the individual pays extra contributions and foregoes pensions over this time interval, which adds up to a total loss $\tau_{R} x$. The public budget improves by the same amount. This "participation tax revenue" $\left(\tau_{2}+p\right) x=p-\tau_{2}$ is equal to maximum pension spending $p$, reduced by the contribution $\tau_{2}$ from the future generation.

With lump-sum pensions, $\tau_{R}=\tau_{2}+p$ and $\tau_{L}=\tau_{1}$. Using the retirement response to an increase in contribution-financed flat pensions in Eq. 32, as well as $\hat{x}=-\eta \hat{\tau}_{R}$, yields the total impact on the present value of the PAYG budget:

$$
d T=\left[1-\frac{\tau_{L}}{1-\tau_{L}} \sigma\right] \cdot L d \tau_{1}+\left[1-\frac{\tau_{R}}{1-\tau_{R}} \eta\right] \cdot \frac{x}{1-x} \frac{2}{\nabla R} d \tau_{2} .
$$

According to Eq. 35, the present value of the budget impact depends on the size of the induced labor supply response on both the intensive and extensive margins.

The marginal excess burden is defined as the marginal, income equivalent welfare loss per additional unit of net tax revenue raised, expressed in present value over all periods. Using Eqs. 33 and 35, we obtain:

$$
\Gamma \equiv-\frac{d \Phi}{d T}=\frac{\frac{\tau_{L}}{1-\tau_{L}} \sigma \cdot \omega_{L}+\frac{\tau_{R}}{1-\tau_{R}} \eta \cdot \omega_{x}}{1-\frac{\tau_{L}}{1-\tau_{L}} \sigma \cdot \omega_{L}-\frac{\tau_{R}}{1-\tau_{R}} \eta \cdot \omega_{x}},
$$

where weights $\omega_{L} \equiv L /\left[L+\frac{x}{1-x} \frac{2}{\nabla R}\right]$ and $\omega_{x} \equiv \frac{x}{1-x} \frac{2}{\nabla R} /\left[L+\frac{x}{1-x} \frac{2}{\nabla R}\right]$ indicate the relative importance of the intensive and extensive margins, such that $\omega_{L}+$ $\omega_{x}=1$. Moreover, the marginal cost of public funds is one plus the marginal excess burden:

$$
\mathrm{MCPF}=1+\Gamma=\frac{1}{1-\frac{\tau_{L}}{1-\tau_{L}} \sigma \cdot \omega_{L}-\frac{\tau_{R}}{1-\tau_{R}} \eta \cdot \omega_{x}} .
$$

In raising the contribution rate to pay for a pension rise, this policy causes people to choose early retirement. Each unit of earlier retirement causes a double burden on the fiscal budget equal to the participation tax rate. The general structure of the MCPF formula in Eq. 37 is parallel to that found in Kleven and Kreiner (2006), who also considered the welfare consequences of tax and benefit changes in a static model, and Immervoll et al. (2007). 
Their analyses are applied here with appropriate modifications to characterize the excess burden of public pensions. The excess burden with respect to the retirement decision is driven by the measures of the participation tax rate, or implicit retirement tax, as suggested by Gruber and Wise (1999b, 2005). The relevant retirement elasticity for Germany is estimated by Börsch-Supan (2000).

\section{Parametric pension reform}

\subsection{Stronger tax-benefit link}

Many countries recently reformed their PAYG pension systems. To undo some of their damaging labor market effects and, in particular, to raise the average retirement age, policy makers have aimed primarily at strengthening the tax-benefit link and introducing a greater degree of actuarial fairness. For example, in order to strengthen old-age labor market participation, Austria has introduced substantial supplements to regular pensions when work is continued beyond the statutory retirement age and pension discounts, or "penalties," for early retirement. Further, the length of the calculation period has been significantly prolonged, i.e., the number of years of past earnings that count towards future pensions has been increased. In addition, the pension system was harmonized so that some occupational groups, such as civil servants who previously received pensions largely unrelated to past earnings, have been integrated into the same earnings-linked system. These measures represent different ways of strengthening the tax-benefit link by making it more widespread, thereby reducing the importance of flat lump-sum pensions. ${ }^{21}$

Within our simple framework, we can analyze this policy initiative by considering an increase in the fixed component $m_{0}$ of the conversion factor $m=\alpha /(1-x)+m_{0}$. To avoid complex calculations that yield no additional insights, we set $m_{0}=0$ in the initial equilibrium and allow $\alpha \in[0,1]$. Since this clearly raises earnings-linked pension levels, we endogenously cut the lump-sum pension component $b$ to satisfy the PAYG budget constraint when the statutory contribution rate is kept constant. In Appendix B, we compute (see Eqs. 58-62) the partial effects on the size of the earnings-linked pension and the participation tax rate. Among other results, we find that an increased conversion factor directly raises the pension level. It also lowers the effective tax rate $\tau_{L}$ of young workers because they individually expect larger future pensions when working more. This stimulates labor supply, augments the assessment base, and further raises pension size. However, a larger pension raises the participation tax rate $\tau_{R}$. On the other hand, this incentive for early

\footnotetext{
${ }^{21}$ See Knell et al. (2006) for an informative description of pension reform in Austria. Fehr et al. (2003) study, by means of numerical simulations of the Norwegian economy, the implications of reforms that reduce the importance of the nonactuarial component of pensions.
} 
Fig. 2 Tighter tax-benefit link

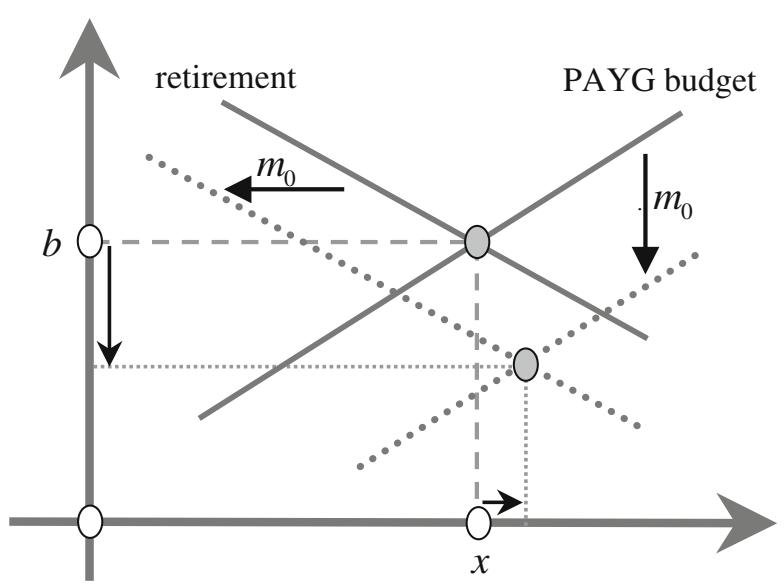

retirement is mitigated by the fact that the policy measure also raises the pension supplement $p$ that becomes available upon choosing a marginally higher retirement age. It must be kept in mind, nevertheless, that the flat pension is endogenously cut to sustain the PAYG budget, which, in turn, causes people retire later. To verify our logic, we solve the system Eqs. 50 and 52, starting from a position of $m_{0}=0$, and noting $\tau_{R}^{\prime}=\varepsilon=0$ :

$$
\begin{aligned}
\hat{x} & =\eta \cdot\left[\frac{\partial p}{\partial m_{0}}-\frac{\partial \tau_{R}}{\partial m_{0}}\right] \frac{1}{\nabla} \frac{d m_{0}}{1-\tau_{R}}>0, \\
d b & =-\left[\frac{\tau_{R}}{1-\tau_{R}} \frac{x}{1-x} \eta \frac{\partial \tau_{R}}{\partial m_{0}}+\frac{\partial p}{\partial m_{0}}\right] \frac{1}{\nabla} d m_{0}<0,
\end{aligned}
$$

where $\nabla>0$ is given in Eq. 21. The signs of the comparative static effects depends on signs of the terms in square brackets in Eq. 38. Employing the appropriate partial derivative expressions stated in Appendix B, we obtain:

$$
\frac{\partial p}{\partial m_{0}}-\frac{\partial \tau_{R}}{\partial m_{0}}=\tau\left[(1-x)+\frac{\tau-\tau_{L}}{1-\tau_{L}} \cdot \sigma L\right]>0 .
$$

Hence, a tighter tax-benefit link raises the retirement age, $\hat{x}>0$, and reduces the lump-sum pension level, $d b<0$. In addition, the partial derivatives in Eqs. 59-62 imply $\partial \tau_{R} / \partial m_{0}>0$ and $\partial p / \partial m_{0}>0$. Moreover, the lump-sum pension falls to such an extent that in equilibrium, despite of the direct effect $\partial \tau_{R} / \partial m_{0}>0$, the participation tax rate declines, which increases $x$. Figure 2 illustrates the response to the reform. ${ }^{22}$

\footnotetext{
${ }^{22}$ The third column of Table 1 shows the responses of the effective tax rates, labor supply decisions, and flat pensions to an increase in $m_{0}$.
} 
Noting the pension formula Eq. 14 and taking the differential of Eq. 12, with $\varepsilon=0$ due to $m_{0}=0$ initially, yields the equilibrium response of the participation tax:

$$
\hat{\tau}_{R}=\frac{\partial p}{\partial m_{0}} \cdot \frac{d m_{0}}{1-\tau_{R}}+\frac{d b}{1-\tau_{R}}-(1-x) \frac{\partial p^{\prime}}{\partial m_{0}} \cdot \frac{d m_{0}}{1-\tau_{R}}<0 .
$$

Substituting the equilibrium changes of retirement age and lump-sum pensions as noted in Eq. 38 and using the partial effects stated in Eq. 39 and Appendix B, we find, after some lengthy computations, $\hat{x}=-\eta \cdot \hat{\tau}_{R}>0$, with $\hat{x}>0$ as in Eq. 38. This reflects the fact that all retirement incentives are summarized in the participation tax rate.

The intensive labor supply response of young workers, $\hat{L}=-\sigma$. $\hat{\tau}_{L}$, depends on the equilibrium change of the implicit tax rate $\tau_{L}=$ $\tau[1-(1-x) m / R]$. Since the statutory contribution rate remains constant, the log-differential yields

$$
\hat{\tau}_{L}=-\frac{(1-x) \tau / R}{1-\tau_{L}} \cdot d m_{0},
$$

which implies that the tax-benefit link reduces the implicit tax rate on young workers, thereby stimulating intensive labor supply. Under the conditions stated above, a stronger tax-benefit link reduces the effective tax rates on both margins of aggregate labor supply, leading, according to Eq. 27, to (potentially) substantial welfare gains.

\subsection{Greater actuarial fairness}

We next explore the benefits of introducing a greater degree of actuarial fairness. Specifically, we first consider the effects of strengthening the taxbenefit link by raising the conversion factor so that pension earnings are more sensitive to the retirement date. The scenario, thus, involves an increase in the parameter $\alpha$, where the conversion factor is $m=\alpha /(1-x)$, with $m_{0}=0$. To keep the system sustainable when past earnings translate into more generous pensions, the lump-sum pension must be cut. We calculate in the Appendix, using Eqs. 63-66, the partial effects for any given retirement date $x$ and find that the participation tax rate is reduced $b^{23} \partial \tau_{R} / \partial \alpha=-\tau$, while the

\footnotetext{
${ }^{23}$ In the specific case considered here, we can obtain a closed form solution: since $z^{\prime}=1$, we have $p^{\prime}=\tau\left[m+m^{\prime} z\right]$. Using $\tau_{R}=\tau+p-(1-x) p^{\prime}$ and $(1-x) m^{\prime}=m$, we then derive $\tau_{R}=$ $b+(1-\alpha) \tau$.
} 
earnings-linked pension component becomes larger, $\partial p / \partial \alpha>0$. Solving Eqs. 50 and 52 yields: ${ }^{24}$

$$
\begin{aligned}
\hat{x} & =\eta \cdot \frac{\tau+\partial p / \partial \alpha}{\nabla} \cdot \frac{d \alpha}{1-\tau_{R}}>0, \\
d b & =-\left[\left(1+\frac{\tau-\tau_{L}}{1-\tau_{L}} \sigma\right) L+\left(1-\frac{\tau_{R}}{1-\tau_{R}} \eta\right) x\right] \frac{\tau}{(1-x) \nabla} \cdot d \alpha,
\end{aligned}
$$

which imply an increase in the retirement date, $\hat{x}>0$. If the earnings-linked component becomes larger, the lump-sum pension must be cut, $d b<0$, except for extreme cases..$^{25}$ Moreover, the policy change is strictly welfare improving. Since $\varepsilon=0$, the participation tax rate changes by $\hat{\tau}_{R}=\frac{\partial p}{\partial \alpha} \frac{d \alpha}{1-\tau_{R}}+\frac{d b}{1-\tau_{R}}-$ $(1-x) \frac{\partial p^{\prime}}{\partial \alpha} \frac{d \alpha}{1-\tau_{R}}$. As before, substituting the solutions from Eq. 42 yields, after some manipulations, the result satisfying $\hat{x}=-\eta \cdot \hat{\tau}_{R}$. The rise in $\alpha$ also leads to a decline in the implicit tax rate on younger workers. The results with respect to the effective tax rates are summarized as follows:

$$
\hat{\tau}_{R}=-\frac{\tau+\partial p / \partial \alpha}{\nabla} \cdot \frac{d \alpha}{1-\tau_{R}}<0, \quad \hat{\tau}_{L}=-\frac{\tau}{R} \cdot \frac{d \alpha}{1-\tau_{L}}<0 .
$$

Since both effective tax rates fall, aggregate labor supply on the intensive and extensive margins is stimulated. Depending on the magnitude of the initial labor market distortions, aggregate efficiency improves.

The scenario discussed above not only introduces more actuarial fairness but also makes earnings-linked pensions more generous, since it raises the conversion factor. To a large extent, however, recent pension reform policy is dictated by the need to restore fiscal sustainability, a goal hardly compatible with replacing a greater part of past earnings. To consider situations closer to actual policy challenges, we evaluate the following reform scenario: raise the parameter $\alpha$ to introduce more actuarial fairness and at the same time cut the coefficient $m_{0}$ to prevent pensions from becoming more generous:

$$
d m_{0}=-\frac{d \alpha}{1-x} \Rightarrow d m=\frac{m}{1-x} \cdot d x .
$$

The scenario implies that the conversion factor $m=\alpha /(1-x)+m_{0}$ remains constant, $m=\bar{m}$, for any given retirement behavior. The conversion factor increases only if the policy measure leads workers to postpone retirement. To keep calculations simple, we start from an initial situation of $m_{0}=0$ so that $m^{\prime}=m /(1-x){ }^{26}$

\footnotetext{
${ }^{24}$ If the coefficient $m_{0}=0$ so that $(1-x) m^{\prime}=m$, the following restrictions can be used: $z^{\prime}=1$ and $\Psi=0=z^{\prime \prime}$, hence, $\tau_{R}^{\prime}=\varepsilon=0$, as well as $\partial \tau_{R} / \partial \alpha=-\tau$. From Eq. 65, we obtain $(1-x) \frac{\partial p^{\prime}}{\partial \alpha}=$ $\tau+\tau\left[\frac{z}{1-x}+m \frac{\partial z}{\partial \alpha}\right]=\tau+\frac{\partial p}{\partial \alpha}$, where $\frac{\partial p}{\partial \alpha}=\frac{\tau}{1-x}\left(z+\frac{\tau-\tau_{L}}{1-\tau_{L}} \sigma L\right)$ and $\tau-\tau_{L}=\alpha \tau / R$.

${ }^{25} \mathrm{~A}$ limited countervailing effect arises, since the pension is paid over a shorter period, which allows the possibility of a larger pension, when retirement is postponed.

${ }^{26}$ Strictly speaking, $m_{0}<0$ after the policy change, to offset the increase in $m$ due to a higher $\alpha$.
} 
To derive the comparative static effects and the welfare consequences of this policy experiment, we need to determine the partial effects on pensions $p$, the participation tax rate $\tau_{R}$, and the pension supplement $p^{\prime}$. To do so, we impose the policy change $d m_{0}=-\frac{d \alpha}{1-x}$ and evaluate derivatives at the initial position $m_{0}=0$ and $m=\alpha /(1-x)$. Using Eqs. 59 and 60 and Eqs. 64 and 65, as well as $(1-x) m \tau / R=\tau-\tau_{L}$ from the definition of the effective tax rate, we show that the partial effects on pension earnings completely cancel. The result is due to the fact that the policy initiative, for a given retirement date, holds the conversion factor constant:

$$
\begin{aligned}
& \frac{\partial p}{\partial \alpha} d \alpha+\frac{\partial p}{\partial m_{0}} d m_{0}=\left[(1-x) \frac{\partial p}{\partial \alpha}-\frac{\partial p}{\partial m_{0}}\right] \cdot \frac{d \alpha}{1-x}=0, \\
& \frac{\partial \tau_{R}}{\partial \alpha} d \alpha+\frac{\partial \tau_{R}}{\partial m_{0}} d m_{0}=\left[(1-x) \frac{\partial \tau_{R}}{\partial \alpha}-\frac{\partial \tau_{R}}{\partial m_{0}}\right] \cdot \frac{d \alpha}{1-x}=-\tau z \cdot \frac{d \alpha}{1-x}<0, \\
& \frac{\partial p^{\prime}}{\partial \alpha} d \alpha+\frac{\partial p^{\prime}}{\partial m_{0}} d m_{0}=\left[(1-x) \frac{\partial p^{\prime}}{\partial \alpha}-\frac{\partial p^{\prime}}{\partial m_{0}}\right] \cdot \frac{d \alpha}{1-x}=\frac{\tau z}{1-x} \cdot \frac{d \alpha}{1-x}>0 .
\end{aligned}
$$

The partial effect on the participation tax rate follows upon substituting Eqs. 62 and 66 and is negative: greater actuarial fairness is designed to reduce the participation tax and to induce postponed retirement. To achieve this, the government increases the pension supplement $p^{\prime}$ that becomes available for a marginal delay in retirement.

The equilibrium impact of the policy reform is found, as before, by solving the system Eqs. 50 and 52. Using the results given above and noting $\tau_{R}^{\prime}=\varepsilon=0$ if evaluated at $m_{0}=0$, we calculate:

$$
\hat{x}=\eta \cdot \frac{1}{1-\tau_{R}} \frac{\tau z}{\nabla} \cdot \frac{d \alpha}{1-x}>0, \quad d b=\eta \cdot \frac{\tau_{R}}{1-\tau_{R}} \frac{x}{1-x} \frac{\tau z}{\nabla} \cdot \frac{d \alpha}{1-x}>0,
$$

where $\nabla \equiv 1+\frac{\tau_{R}}{1-\tau_{R}} \frac{x}{1-x} \eta>0$. As indicated, the policy experiment in Eq. 44 keeps pension size fixed if the retirement date does not change but offers larger pension supplements when retirement is postponed. It thus succeeds to reduce the participation tax and to encourage later retirement. This scenario also raises the lump-sum pension $b$-in sharp contrast to the previous case in which the conversion factor $m$ was allowed to vary-since it expands the assessment base and shortens the retirement period. ${ }^{27}$

\footnotetext{
${ }^{27}$ The fourth and fifth columns of Table 1 list, respectively, the qualitative responses of implicit taxes, intensive and extensive labor supply, and flat pensions to greater actuarial fairness under the scenario in which the conversion factor is allowed to adjust and the one in which it held fixed, i.e., $m=\bar{m}$.
} 
In equilibrium, with $\varepsilon=0$, the effect of retirement choice $x$ on $\tau_{R}$ disappears. Substitution of Eq. 45 shows that the participation tax rate falls by:

$$
\hat{\tau}_{R}=-\frac{\tau z}{\left(1-\tau_{R}\right) \nabla} \cdot \frac{d \alpha}{1-x}<0,
$$

which confirms $\hat{x}=-\eta \cdot \hat{\tau}_{R}$ and is consistent with Eq. 46. A welfare evaluation employing Eq. 27 requires the calculation of the effect on the effective tax rate on young workers and their intensive labor supply response. Imposing the policy change and calculating the differential of the implicit tax rate $\tau_{L}=$ $\tau[1-(1-x) m / R]$ at $m_{0}=0$ yields:

$$
d \tau_{L}=\frac{\tau}{R} \cdot[m d x-(1-x) d m]=0 .
$$

According to Eq. 48, the effective tax rate on young workers is independent of the policy scenario in Eq. 44, implying that first-period labor supply remains constant. The experiment fails to reduce distortions faced by young workers and, thus, cannot promise any further efficiency gains on that margin. The main advantage of the policy package is the reduction of the participation tax rate. By encouraging later retirement, it potentially results in welfare gains on the extensive margin.

\section{Conclusion}

The potential labor market impact of pension reform is a prime policy concern. Aging and the socioeconomic trend to early retirement not only impose financial stress on the system, but are also an important factor in restraining aggregate employment. The need to provide incentives for continued labor market participation of older workers has, thus, received increasing attention among policy makers. For example, the tax character and the harmful impact on labor supply incentives of prime-age workers is a particular concern. Recent reform initiatives in many countries also aim at reducing the large participation tax rates incorporated in current pension systems. Pension formulas have been modified to offer income supplements for each year of delayed retirement and pension "penalties" have been imposed when earlier retirement is chosen. Other measures seek to improve incentives of prime-age workers by strengthening the tax-benefit link. In Austria, recent pension reform includes a "harmonization" of the system, with the consequence that civil servants and other groups who have previously received lump-sum pensions unrelated to past earnings, are now included in the same earnings-linked pension system. Moreover, Austria, along with other countries, has lengthened the calculation period for the pension assessment base so that not only the best 5 or 10 years, but the entire earnings history matters in determining the size of the pension. The purpose is to raise the share of prime-age workers who are subject to a tax-benefit link and will, as a result, perceive that their pension contributions 
have a lower tax component. As such, these reforms are suitable to stimulate labor supply and employment among younger workers.

This paper has proposed a simple model that captures the interaction between labor supply incentives of prime-age workers and incentives for labor market participation of those near retirement. We show that the joint policy goals of stimulating young and old-age labor supply can conflict with each other. In a system with a tax-benefit link, raising the retirement age tends to raise the effective tax faced by young, prime-age workers. When the retirement date is postponed, the extra pension benefits expected by a young worker from increased earnings are obtained only in the more distant future and over a shorter retirement period. Consequently, these future earnings are discounted more heavily, which raises the tax component of any given contribution. For the same reasons, we find that an exogenous, socioeconomic trend to early retirement raises prime-age labor supply, which tends to offset the reduction in aggregate employment due to lower old-age labor market participation. In view of this trade-off, policy makers should be careful to design reforms in a way that strengthens both margins of labor supply in an aging society.

Fortunately, our analysis shows that some recent reform approaches can attain this objective. If it is possible to cut lump-sum pensions, for example, by "harmonizing" the system, an increase in the tax-benefit link indeed tends to stimulate both margins of labor supply, regardless of whether the link is also made actuarially fair with respect to the retirement date. However, if the conversion factor determining pension size conditional on past earnings is made more sensitive with respect to retirement age without raising its overall magnitude, then such a reform, while encouraging old-age labor market participation, does not stimulate employment among prime-age workers. Nevertheless, this scenario shows that any given increase in the tax-benefit link is much preferred if it is also made actuarially fair in the sense of Gruber and Wise, compared to one that is not sensitive to a worker's retirement choice.

\section{Appendix}

\section{A Comparative statics}

In part $A$ of the Appendix, we calculate the log-linearized versions of the retirement condition Eq. 12 and the PAYG pension budget Eq. 19. The resulting expressions take into account, subject to pension earnings Eq. 14, the intensive labor supply decision Eq. 11, and solve-in terms of percentage changes relative to an initial equilibrium - for the equilibrium retirement date $x$ and flat pension $b$. They serve as the basis for our comparative statics analysis in Sections 2, 3, and 4.

To begin, we note that pension earnings are a complex function of the parameters of the PAYG system: $p\left(x, b ; \tau, m_{0}, \alpha\right)=m\left(x ; m_{0}, \alpha\right) \tau z\left(x ; \tau, m_{0}, \alpha\right)+b$. Obviously, $p^{\prime} \equiv \partial p / \partial x$ is independent of the flat pension $b$. We derive how the relative change $\hat{\tau}_{R} \equiv d \tau_{R} /\left(1-\tau_{R}\right)$ of the participation tax rate depends 
on changes in retirement behavior, $x$, and pension parameters $\tau, m_{0}, \alpha$, and $b$. The effective tax rate $\tau_{R} \equiv \tau+p-(1-x) p^{\prime}$ is defined in Eq. 12. Defining the elasticity $\varepsilon \equiv \tau_{R}^{\prime} x /\left(1-\tau_{R}\right)$, where $\tau_{R}^{\prime}$ is given in Eq. 16, and noting that pension parameters affect the participation tax rate by their impact on $p$ and $p^{\prime}$, we obtain:

$$
\hat{\tau}_{R}=\varepsilon \cdot \hat{x}+\frac{d b}{1-\tau_{R}}+\frac{\partial \tau_{R}}{\partial \tau} \frac{d \tau}{1-\tau_{R}}+\frac{\partial \tau_{R}}{\partial m_{0}} \frac{d m_{0}}{1-\tau_{R}}+\frac{\partial \tau_{R}}{\partial \alpha} \frac{d \alpha}{1-\tau_{R}} .
$$

The derivatives of $\tau_{R}$ will be derived for specific policy scenarios in part B of the Appendix. Substituting Eq. 49 into the retirement response noted in Eq. 13, we derive, after rearranging, the following equation for the impact on retirement in terms of parametric shifts and the change $d b$ in the endogenous level of flat pensions:

$$
\hat{x}=-\frac{\eta}{1+\eta \varepsilon} \frac{1}{1-\tau_{R}}\left[d b+\frac{\partial \tau_{R}}{\partial \tau} d \tau+\frac{\partial \tau_{R}}{\partial m_{0}} d m_{0}+\frac{\partial \tau_{R}}{\partial \alpha} d \alpha+\left(1-\tau_{R}\right) \hat{\gamma}\right] .
$$

This equation corresponds to the retirement locus in Figs. 1 and 2. It is downward sloping, since a higher flat pension induces, holding $\tau, m_{0}, \alpha$ constant, earlier retirement.

The other constraint that pins down the equilibrium is the condition for budget balance in Eq. 19: $\tau \cdot(1+x)=(1-x) p$. Taking the differential of revenues and spending yields:

$$
(1+x) d \tau+\tau d x=(1-x)\left[p^{\prime} d x+\frac{\partial p}{\partial \tau} d \tau+\frac{\partial p}{\partial m_{0}} d m_{0}+\frac{\partial p}{\partial \alpha} d \alpha+d b\right]-p d x
$$

Using the fact that $\tau_{R}=\tau+p-(1-x) p^{\prime}$, we solve for $d b$ in terms of $\hat{x}$ and the shifts in the pension parameters:

$$
d b=\frac{\tau_{R} x}{1-x} \cdot \hat{x}+\left[\frac{1+x}{1-x}-\frac{\partial p}{\partial \tau}\right] \cdot d \tau-\frac{\partial p}{\partial m_{0}} \cdot d m_{0}-\frac{\partial p}{\partial \alpha} \cdot d \alpha .
$$

This equation corresponds to the PAYG budget locus in Figs. 1 and 2. It is upward sloping since an increase in retirement age relaxes the pension budget and allows for a larger flat pension as long as the participation tax rate $\tau_{R}$ is positive. This is intuitive, since the participation tax measures the net fiscal loss to households and, thus, the net gain to the system, if retirement is marginally postponed. The tax rate $\tau_{R}$ captures the extra tax paid plus the pension earnings foregone minus the increase in pensions over the remaining life-time $1-x$, corresponding to the number of pensioners in the cross-section of the population.

The solution of Eqs. 50 and 52 determines the reduced-form, equilibrium expressions for the retirement response and the size of the flat, lump-sum pension payments in terms of the changes in the system parameters $\left(\tau, m_{0}, \alpha\right)$ and the preference parameter $\gamma$. This solution yields, in turn, the reactions 
of the other variables of interest, e.g., the response of intensive labor supply $\hat{L}$ of young workers, the latter due, as discussed above in Eqs. 10 and 11, to the impact of the participation decision $\hat{x}$ on the implicit tax $\hat{\tau}_{L}$. We can also infer the impact on the participation tax $\hat{\tau}_{R}$ of the old, which yields the welfare change according to Eq. 27.

\section{B Effects on the participation tax rate}

In Appendix B, we derive the responses of the participation tax to changes in, respectively, the contribution rate, the tax-benefit link, and the degree of actuarial fairness. Combined with Eqs. 50 and 52, the resulting partial derivatives determine the equilibrium shifts in old-age participation and flat pensions for the policy reforms considered in Sections 3 and 4. All the subsequent partial derivatives are calculated for a given retirement date.

Statutory tax rate Using $\tau_{R}=\tau+p-(1-x) p^{\prime}$ from Eq. 12, we compute first the effect of an increase in the contribution rate:

$$
\frac{\partial \tau_{R}}{\partial \tau}=1+\frac{\partial p}{\partial \tau}-(1-x) \frac{\partial p^{\prime}}{\partial \tau} .
$$

The impact on earnings-linked pensions depends on the reaction of the assessment base, $z=x+L$, which, in turn, is driven by first-period labor supply in Eq. 9. Using $\tau_{L}$ as given in Eq. 6 and holding $x$ constant, we find that a higher contribution rate discourages intensive labor supply and thereby erodes the assessment base:

$$
\tau \frac{\partial z}{\partial \tau}=\tau \frac{\partial L}{\partial \tau_{L}} \frac{\partial \tau_{L}}{\partial \tau}=-\frac{\tau_{L}}{1-\tau_{L}} \cdot \sigma L<0 .
$$

In calculating the effect on pensions $p=m \tau z+b$, we note that the conversion factor $m=\frac{\alpha}{1-x}+m_{0}$ and its derivative $m^{\prime}=\frac{\alpha}{(1-x)^{2}}=\frac{m-m_{0}}{1-x}$ are independent of $\tau$. A higher contribution rate thus affects the pension level and the pension increment $p^{\prime}=\tau \cdot\left[z m^{\prime}+m z^{\prime}\right]$ that is offered if retirement is marginally postponed:

$$
\frac{\partial p}{\partial \tau}=m\left[z+\tau \frac{\partial z}{\partial \tau}\right], \quad \frac{\partial p^{\prime}}{\partial \tau}=m\left[z^{\prime}+\tau \frac{\partial z^{\prime}}{\partial \tau}\right]+m^{\prime}\left[z+\tau \frac{\partial z}{\partial \tau}\right] .
$$

The term $z^{\prime}=1+L^{\prime}=1-\Psi$, with $\Psi \equiv \frac{\sigma L}{1-\tau_{L}} \cdot \frac{m_{0} \tau}{R}$, follows from Eq. $11 .{ }^{28}$ Assuming a fixed wage elasticity of labor supply $\sigma$, we obtain:

$$
\tau \cdot \frac{d z^{\prime}}{d \tau}=-\Psi \cdot\left[1+(1-\sigma) \frac{\tau_{L}}{1-\tau_{L}}\right]
$$

\footnotetext{
${ }^{28}$ Indeed, $\Psi$ depends on $m_{0}$ rather than $m$. Moreover, both $m_{0}$ and $m$ are independent of $\tau$.
} 
Using the relationships $(1-x) m^{\prime}=m-m_{0}=\alpha /(1-x)$ and substituting the relevant derivatives into Eq. 53, we find:

$$
\begin{aligned}
\frac{\partial \tau_{R}}{\partial \tau}= & 1-\alpha+m_{0} \cdot\left[z-(1-x)-\frac{\tau_{L}}{1-\tau_{L}} \sigma L\right] \\
& +(1-x) m \cdot \Psi\left(2+(1-\sigma) \frac{\tau_{L}}{1-\tau_{L}}\right) .
\end{aligned}
$$

From this general expression, we deduce several cases: full actuarial fairness: $\alpha=1, m_{0}=\Psi=0$, (with $b=0$ ) and hence $\partial \tau_{R} / \partial \tau=0$. While the participation tax rate is zero in this case, there remains a positive implicit tax on young workers, $\tau_{L}=\tau \cdot[1-1 / R]$, which is smaller than the statutory rate because PAYG contributions earn no interest. The other extreme case is no tax-benefit link, $\alpha=m_{0}=0$, so that $\partial \tau_{R} / \partial \tau=1$.

The case with a fixed conversion factor independent of retirement behavior, $m=m_{0}$ and $\alpha=0$, yields an intermediate case. The square bracket in Eq. 57 can safely be assumed positive, at least if the labor supply elasticity is not too large. In our simple model, the worker-retiree ratio is $(1+x) /(1-x)$, which exceeds unity in a realistic setting. If, instead, considering the effective number of workers, $L+x$, and realistically assuming that hours worked of young and older workers are not too different, i.e., $L$ close to 1 , we also have $z=L+$ $x>(1-x)$. Therefore, the first two terms in the square bracket are clearly positive. A natural assumption, which is actually stronger than required, is that the erosion of the assessment base will not be so large as to exceed the net effect of the first two terms in the square bracket.

It will also be instructive to consider the case of fixed first-period labor supply, given by $\sigma=\Psi=0$, which again leads to an increase in the participation tax rate if the statutory tax rate is raised, $\frac{\partial \tau_{R}}{\partial \tau}=1-\alpha+m_{0}[z-(1-x)]>0$, $\alpha \in[0,1]$. By continuity, the total effect on $\frac{\partial \tau_{R}}{\partial \tau}$ remains positive at least for small values of $\sigma$. In any case, the influence of $L$ is likely to be small, given the econometric evidence on the labor supply response of young workers.

Tax-benefit link Consider the effect of a tighter tax-benefit link $m=$ $\alpha /(1-x)+m_{0}$, through a rise in $m_{0}$, starting from $m_{0}=0$. The parameter $\alpha \in[0,1]$ can take arbitrary values, with $\alpha=0$ being one special case. The partial effect on $\tau_{R}=\tau+p-(1-x) p^{\prime}$ is:

$$
\frac{\partial \tau_{R}}{\partial m_{0}}=\frac{\partial p}{\partial m_{0}}-(1-x) \frac{\partial p^{\prime}}{\partial m_{0}} .
$$

Using $\tau_{L}$ as given in Eq. 6, and holding $x$ constant, we find that a tax-benefit link encourages intensive labor supply and thereby expands the assessment base $z=x+L$ :

$$
m \frac{\partial z}{\partial m_{0}}=m \frac{\partial L}{\partial \tau_{L}} \frac{\partial \tau_{L}}{\partial m_{0}}=\frac{\tau-\tau_{L}}{1-\tau_{L}} \cdot \sigma L>0 .
$$


Raising the conversion factor $m_{0}$ affects the pension level, $p=\tau m z+b$, and the pension increment $p^{\prime}=\tau\left[m z^{\prime}+m^{\prime} z\right]$ in Eq. 15 by:

$$
\frac{\partial p}{\partial m_{0}}=\tau\left[z+m \frac{\partial z}{\partial m_{0}}\right], \quad \frac{\partial p^{\prime}}{\partial m_{0}}=\tau\left[z^{\prime}+m \frac{\partial z^{\prime}}{\partial m_{0}}+m^{\prime} \frac{\partial z}{\partial m_{0}}\right] .
$$

Since we evaluate the policy change starting from $m_{0}=0$ in the initial equilibrium, the marginal effect of later retirement on the assessment base is unity, $z^{\prime}=1+L^{\prime}=1$. Given $m_{0}=0$ initially, the term $(1-x) m=\alpha$ and the effective tax rate $\tau_{L}=\tau[1-(1-x) m / R]$ remain constant, and therefore, first-period labor supply, is independent of retirement age. Consequently, we obtain:

$$
\frac{\partial p^{\prime}}{\partial m_{0}}=\tau\left[1+m^{\prime} \frac{\partial z}{\partial m_{0}}\right]
$$

Combining Eqs. 58-61 and noting that $m_{0}=0$ implies $(1-x) m^{\prime}=m$, we find:

$$
\frac{\partial \tau_{R}}{\partial m_{0}}=\tau[z-(1-x)]>0 .
$$

Thus, a strengthening of the tax-benefit link (from an initial value of $m_{0}=0$ ) results in a partial effect on the participation tax rate corresponding to $\partial \tau_{R} / \partial m_{0}=\tau[z-(1-x)]>0$, where the term in square brackets can safely assumed, as before, to be positive.

More actuarial fairness Raising the parameter $\alpha$ not only introduces a tighter tax-benefit link, but also makes it fairer. Again, we assume $m_{0}=0$ initially. The partial impact on the participation tax rate, $\tau_{R}=\tau+p-(1-x) p^{\prime}$, is:

$$
\frac{\partial \tau_{R}}{\partial \alpha}=\frac{\partial p}{\partial \alpha}-(1-x) \frac{\partial p^{\prime}}{\partial \alpha}
$$

Using $\tau_{L}$ in Eq. 6, and holding $x$ constant, we find the pension base $z=x+L$ grows by:

$$
\frac{\partial z}{\partial \alpha}=\frac{\partial L}{\partial \tau_{L}} \frac{\partial \tau_{L}}{\partial \alpha}=\frac{\sigma L}{1-\tau_{L}} \cdot \frac{\tau}{R}>0
$$

The conversion factor changes by $\partial m / \partial \alpha=1 /(1-x)$ and $\partial m^{\prime} / \partial \alpha=$ $1 /(1-x)^{2}$. The tax-benefit link thus affects the pension level $p=m \tau z+b$ and the pension increment $p^{\prime}=\tau\left[m^{\prime} z+m z^{\prime}\right]$ in Eq. 15 according to:

$$
\frac{\partial p}{\partial \alpha}=\tau\left[\frac{z}{1-x}+m \frac{\partial z}{\partial \alpha}\right], \quad \frac{\partial p^{\prime}}{\partial \alpha}=\tau\left[\frac{z}{(1-x)^{2}}+m^{\prime} \frac{\partial z}{\partial \alpha}+\frac{1}{1-x}\right] .
$$


Our assumption of $m_{0}=0$ initially implies that $(1-x) m=\alpha$ does not vary with $x$. Later retirement thus expands the assessment base $z=L+x$ by $z^{\prime}=1$, with $\partial z^{\prime} / \partial \alpha=0$. Combining Eqs. 63-65 yields, upon using $m=(1-x) m^{\prime}$ :

$$
\frac{\partial \tau_{R}}{\partial \alpha}=\frac{\partial p}{\partial \alpha}-(1-x) \frac{\partial p^{\prime}}{\partial \alpha}=-\tau .
$$

Consequently, introducing more actuarially fairness reduces the participation tax rate.

\section{Preferences}

To relate our assumptions on preferences in Section 2.1 to the existing literature, we consider the general life-cycle problem in which we only impose time separability, as is usual in macroeconomics. To be concise, we abstract from the pension system:

$$
V=\max _{c_{1}, l_{1}, l_{2}, x} u\left(c_{1}, l_{1}\right)+\beta u\left(c_{2}, l_{2}, x\right) \quad \text { s.t. } \quad c_{2}=\left(w_{1} l_{1}-c_{1}\right) R+w_{2} l_{2} x .
$$

The modified notation refers to wages $w_{t}$, intensive labor supply $l_{t}, t=1,2$, and the subjective discount factor $\beta$ ( $\equiv 1 / R$ in the main text). Defining partial derivatives as $u_{c}^{1} \equiv \partial u\left(c_{1}, l_{1}\right) / \partial c_{1}, u_{l}^{1} \equiv \partial u\left(c_{1}, l_{1}\right) / \partial l_{1}, u_{c}^{2} \equiv \partial u\left(c_{2}, l_{2}, x\right) / \partial c_{2}$, $u_{l}^{2} \equiv \partial u\left(c_{2}, l_{2}, x\right) / \partial l_{2}$, and $u_{x}^{2} \equiv d u\left(c_{2}, l_{2}, x\right) / d x$, the resulting optimality conditions are:

$$
\frac{u_{c}^{1}}{\beta u_{c}^{2}}=R, \quad-\frac{u_{l}^{1}}{u_{c}^{1}}=w_{1}, \quad-\frac{u_{l}^{2}}{u_{c}^{2}}=x w_{2}, \quad \frac{u_{l}^{1}}{\beta u_{x}^{2}}=\frac{w_{1} R}{w_{2} l_{2}} .
$$

These conditions express the usual tangency conditions, where the marginal rates of substitution are equal to relative prices. For example, the last condition in Eq. 68 refers to the trade-off between the old-age participation rate (retirement date) $x$ and first-period labor supply $l_{1}$. The marginal rate of substitution measures by how much old-age participation must decline to compensate for a marginal increase in first-period labor supply, $d x /\left.d l_{1}\right|_{d V=0}=-u_{l}^{1} /\left(\beta u_{x}^{2}\right)$. The right hand side gives the marginal rate of transformation, i.e., the reduction of old-age participation in exchange for a marginal increase in first-period labor supply such that life-time income is unchanged.

Income effects substantially complicate the comparative static analysis of Eq. 68. To focus on incentive effects, a large part of the literature imposes separability between consumption and labor market activities in each period. Two recent examples are Cigno (2008) and Fenge and Pestieau (2005). Assuming fixed labor supply during the economically active part of the second period, $l_{2}=1$, preferences specialize to:

$$
V=\max _{c_{1}, l_{1}, x} u\left(c_{1}-\varphi\left(l_{1}\right)\right)+\beta u\left(c_{2}-\gamma \phi(x)\right) .
$$


The analysis in Cigno (2008) corresponds to this case, except that he suppresses second period participation and, instead, analyzes individual decisions in the presence of credit constraints. In the absence of the latter, the savings condition is $u_{c}^{1}=\beta R u_{c}^{2}$. Noting $u_{l}^{1}=-u_{c}^{1} \varphi^{\prime}\left(l_{1}\right)$ and $u_{x}^{2}=-u_{c}^{2} \gamma \phi^{\prime}(x)$, optimal labor market activities are given by $w_{1}=\varphi^{\prime}\left(l_{1}\right)$ and $w_{2}=\gamma \phi^{\prime}(x)$. These conditions are identical to Eqs. 6 and 12 in the main text, where the pension system determines consumer prices $w_{1}=1-\tau_{L}$ and $w_{2}=1-\tau_{R}$ and, thereby, the intertemporal trade-off in labor market behavior. In particular, the tradeoff between first and second period labor supply still corresponds to the last condition in Eq. 68, except that the marginal rate of substitution reduces to:

$$
d x /\left.d l_{1}\right|_{d V=0}=-\frac{R \varphi^{\prime}\left(l_{1}\right)}{\gamma \phi^{\prime}(x)} .
$$

To reiterate, since this paper focusses on labor market behavior rather than savings, we further specialize preferences in Eq. 2 to be linear in consumption. Given $u_{c}^{t}=1, t=1,2$, the savings condition above requires $1=\beta R$. Aside from fixing the interest rate, this simplification leads to no further restrictions on labor market behavior.

Given factor prices, the impact of the pension system on $l_{1}, x$ and $s$ follows, in general, from the comparative statics of Eq. 68, where the third condition is omitted if $l_{2}=1$ is fixed. As long as income effects are 'sufficiently small' compared to substitution effects, our qualitative results are not affected.

Acknowledgements The paper was written under the CESifo initiative on "How to construct Europe". We gratefully acknowledge the financial support from the Leibniz Gemeinschaft (WGL) of German research institutes. We are indebted as well to the Oesterreichische Nationalbank (Jubilaeumsfondsprojekt Nr. 10244, Fisher) and the University of St. Gallen's Research Fund (Keuschnigg) for their generous financial assistance. The paper was presented at the CESifo Area Conference on Employment and Social Protection in Munich, May 2007. We thank our discussant A. Balestrino and seminar participants for their valuable comments. We are particularly grateful to two anonymous referees and the editor A. Cigno for very helpful comments.

\section{References}

Blöndal S, Scarpetta S (1999) The retirement decision in OECD countries. OECD Economics Department Working Papers, No. 202

Bommier A, Leroux ML, Lozachmeur JM (2005) Varying life expectancy and social security. Working Paper

Börsch-Supan A (2000) Incentive effects of social security on labor-force participation: evidence in Germany and Across Europe. J Public Econ 78:25-49

Börsch-Supan A (2003) labor markets effects of population aging. Rev Labor Econ Ind Relat 17:5-44

Bovenberg LA (2003) Financing retirement in the European union. Int Tax Public Financ 10:713734

Bratberg E, Holmås TH, Thøgersen $\varnothing$ (2004) Assessing the effects of an early retirement program. J Public Econ 17:387-408

Breyer F, Hupfeld S (2007) On the fairness of early retirement provisions. In: Paper presented at CESifo area conference on employment and social protection, Munich, May 2007

Breyer F, Kifmann M (2002) Incentives to retire later-a solution to the social security crisis? J Pension Econ Financ 1:111-130 
Calvo GA, Obstfeld M (1988) Optimal time consistent fiscal policy with finite lifetimes. Econometrica 56:411-432

Cigno A (2008) Is there a social security tax wedge? Labour Econ 15:68-77

Cremer H, Pestieau P (2003) The double dividend of postponing retirement. Int Tax Public Financ 10:419-434

Cremer H, Lozachmeur JM, Pestieau P (2004) Social security, retirement age and optimal income txation. J Public Econ 88:2259-2281

Demmel R, Keuschnigg C (2000) Funded pensions and unemployment. FinanzArchiv 57:22-38

Diamond PA (2004) Social security. Am Econ Rev 94:1-24

Diamond PA, Mirrlees JA (1978) A model of social insurance with variable retirement. J Public Econ 10:295-336

Diamond PA, Orszag PR (2005) Saving social security. J Econ Perspect 19:11-32

Disney R (2004) Are contributions to public social security programmes a tax on employment. Econ Policy 39:267-311

Fehr H, Sterkeby WI, Thøgersen $\varnothing$ (2003) Social security reforms and early retirement. J Popul Econ 16:345-361

Feldstein M (1974) Social security, induced retirement, and aggregate capital accumulation. J Polit Econ 82:905-926

Feldstein M (2005a) Rethinking social insurance. Am Econ Rev 95:1-24

Feldstein M (2005b) Structural reform of social security. J Econ Perspect 19:33-55

Feldstein M, Liebman JB (2002) Social security. In: Auerbach AJ, Feldstein M (eds) Handbook of public economics, vol 4. Elsevier, Amsterdam, pp 2245-2324

Feldstein M, Samwick A (1992) Social security rules and marginal tax rates. Natl Tax J 45:1-22

Feldstein M, Samwick A (2002) Potential paths of social security reform. MIT, Cambridge, ch 16, pp 181-224

Fenge R, Pestieau P (2005) Social security and early retirement. MIT, Cambridge

Fenge R, Werding M (2004) Ageing and the tax implied in public pension schemes: simulations for selected OECD countries. Fisc Stud 25:159-200

Galasso V, Profeta P (2004) Lessons for an ageing society: the political sustainability of social security systems. Econ Policy 19(38):63-115

Gruber J, Wise DA (1999a) Social security and retirement around the world: introduction and summary. In: Gruber J, Wise D (eds) Social security and retirement around the world. University of Chicago Press, Chicago (also published in Research in Labor Economics 18, JAI Press Inc., 1999)

Gruber J, Wise DA (eds) (1999b) Social security and retirement around the world. University of Chicago Press, Chicago

Gruber J, Wise DA (2002) Social security programs and retirement around the world: microestimation. NBER Working Paper \#9407

Gruber J, Wise DA (2005) Social security programs and retirement around the world: fiscal implications. NBER Working Paper \#11290

Immervoll H, Kleven HJ, Kreiner CT, Saez E (2007) Welfare reform in European countries: a microsimulation analysis. Econ J 117:1-44

Keuschnigg C (1994) Dynamic tax incidence and intergenerationally neutral reform. Eur Econ Rev 38:343-366

Kleven HJ, Kreiner CT (2006) The marginal cost of public funds: hours of work versus labor force participation. J Public Econ 90:1955-1973

Knell M, Koehler-Toeglhofer W, Prammer D (2006) The Austrian pension system-how recent reforms have changed fiscal sustainability and pension benefits. Austrian National Bank, Vienna

Kotlikoff LJ (1997) Privatizing social security in The United States: why and how. In: Auerbach AJ (ed) Fiscal policy: lessons from economic research. MIT, Cambridge, pp 213-248

Lacomba JA, Lagos F (2006) Population aging and legal retirement age. J Popul Econ 19:507-519

Lau M, Poutvaara P (2006) Social security incentives and human capital investment. Finn Econ Pap 19(1):16-24

Lindbeck A, Persson M (2003) The gains from pension reform. J Econ Lit 41:74-112

Ono T (2003) Social security policy with public debt in an aging economy. J Popul Econ 16:363-387 
Saez E (2002) Optimal income transfer programs: intensive versus extensive labor supply responses. Q J Econ 117:1039-1073

Scarpetta S (1996) Assessing the role of labour market policies and institutional settings on unemployment: a cross-country study. OECD Econ Stud 26:43-98

Sheshinski E (1978) A model of social security and retirement decisions. J Public Econ 10: $337-360$ 